NANO: Brief Reports and Reviews

Vol. 14, No. 5 (2019) 1950063 (16 pages)

(C) World Scientific Publishing Company

DOI: $10.1142 /$ S1793292019500632

\title{
Preparation of Cobalt Ferrite Nanoparticle-Decorated Boron Nitride Nanosheet Flame Retardant and Its Flame Retardancy in Epoxy Resin
}

\author{
Qiaoran Zhang ${ }^{*, \dagger}$, Zhiwei Li*, ${ }^{*,+}$, Xiaohong $\mathrm{Li}^{*, \dagger}$, Laigui $\mathrm{Yu}^{*, \dagger}$, Zhijun Zhang, ${ }^{* \dagger}$ \\ and Zhishen $\mathrm{Wu}^{*, \dagger}, \S$ \\ *National $\mathscr{E}$ Local Joint Engineering Research Center for \\ Applied Technology of Hybrid Nanomaterials \\ Henan University, Kaifeng 475004, P. R. China \\ ${ }^{\dagger}$ Collaborative Innovation Center of Nano Functional Materials and \\ Applications of Henan, Province \\ Henan University, Kaifeng 475004, P. R. China \\ *Zhiweili@henu.edu.cn \\ $\S_{\text {wuzhishen } @ h e n u . e d u . c n}$
}

Received 9 January 2019

Accepted 16 April 2019

Published 15 May 2019

\begin{abstract}
Boron nitride nanosheet (BNNS) decorated with cobalt ferrite nanoparticle (CFN) to afford CFN-BNNS nanohybrid was prepared via a simple hydrothermal route and was well characterized. Subsequently, the as-prepared CFN-BNNS nanohybrid was incorporated into epoxy resin (EP) with the introduction of a weak rotary magnetic field to achieve order orientation, in order to reduce the fire risk and toxic hazards using enhanced shielding effect of BNNS upon combustion. Findings demonstrate that the CFN-BNNS nanohybrid is composed of CFN nanoparticle uniformly dispersed on BNNS surface. Thermal analysis and cone calorimeter data show that the CFN-BNNS nanofiller among EP matrix contributes to improving the char residues and mechanical properties of EP and reducing its fire risk as well as toxic hazards, especially the ordered one is advantageous over the disordered one in reducing the fire risk and toxic hazard. This is because, on the one hand, the orderly aligned BNNS as the physical barrier can more effectively prevent the transfer and diffusion of oxygen and heat. On the other hand, CFN can catalyze the degradation of EP to afford excessive chars on polymer surface; and it is also liable to decomposition during combustion, thereby generating ferrite species to promote EP degradation as well as cobalt species to enhance the oxidation of $\mathrm{CO}$.
\end{abstract}

Keywords: Cobalt ferrite; boron nitride nanosheets; flame retardants; epoxy resin; order orientation.

\section{Introduction}

Epoxy resin (EP) is widely applied in adhesive, aerospace, and building industries as well as in

${ }^{\ddagger, \delta}$ Corresponding authors. insulation appliances, because of its unique physical and chemical properties. ${ }^{1,2}$ However, EP faces fatal hazards associated with its high flammability, 
including thermal hazards and toxic hazards upon combustion. ${ }^{3}$ On the one hand, there is a large amount of heat released during polymer combustion, resulting in violent thermal risks. On the other hand, the excessive release of toxic gases like carbon monoxide ( $\mathrm{CO})$ and black smoke particles mainly composed of organic components can bring about significant toxic risks to the environment and human beings' health. Therefore, it is urgent to improve the fire resistance and smoke suppression properties of EP in order to reduce its fire hazards and broaden its application scopes.

Previous research indicates that the incorporation of halogen-containing flame retardants is valid in cutting down the thermal hazards of polymers. ${ }^{4}$ However, halogen-containing flame retardants can generate toxic black smoke particles during burning process, which is unfavorable for suppressing the toxic hazards of polymers. Therefore, it needs to develop green and highly efficient flame-retardant additives applicable to polymer matrices. In this respect, a variety of twodimensional (2D) inorganic nanofillers, including graphene oxide $(\mathrm{GO}),{ }^{5}$ layered double hydroxide (LDH),${ }^{6}$ montmorillonite, ${ }^{7}$ and molybdenum disulfide $\left(\mathrm{MoS}_{2}\right),{ }^{8}$ could have promising prospect. This is because, on the one hand, 2D inorganic nanofillers exhibit nanoplate structure that exerts "tortuous path" effect during the combustion of polymer, thereby prolonging the heat conductivity path of the fire source into inner matrix and reducing the heat hazards. On the other hand, they exhibit large specific surface area and good mechanical strengths as well as nanolayered structure, which is beneficial to reducing the fire hazards of polymer materials. ${ }^{9-11}$ However, the flame retardance is not enough in the use of such 2D inorganic nanofillers alone, and in particular, the ability to suppress toxic gases and smoke is weak.

Transition metal oxides, especially iron oxi$\operatorname{des}^{12,13}$ and cobalt oxides, ${ }^{14}$ can well reduce the toxic hazards of polymers upon burning. For instance, Liu et al. reported that ferrites obtained by co-precipitation method can effectively suppress the smoke and toxicity of polyurethanepolyisocyanurate flame-retardant foams. ${ }^{15}$ Chen et al. said that $\alpha-\mathrm{FeOOH}$ as a smoke suppression agent can significantly reduce the smoke production rate and heat release rate of intumescent flameretardant epoxy resin. ${ }^{16}$ We found in our previous research that mesoporous zinc ferrite prepared by a simple solvothermal method can greatly reduce the smoke release especially toxic CO of EP, showing excellent smoke suppression ability. ${ }^{17}$ Moreover, some publications demonstrate that cobalt compounds can well promote the oxidation of $\mathrm{CO}$ thereby restraining the hazards. For example, $\mathrm{CoOOH}$ blended with $\mathrm{MoS}_{2}$ and $\mathrm{Co}_{3} \mathrm{O}_{4}$ blended with graphene oxide can both effectively catalyze and accelerate $\mathrm{CO}$ oxidation, thereby considerably reducing the release of toxic $\mathrm{CO}$ during combustion. ${ }^{8}$ These researches remind us that, if ferrite and cobalt species can be jointly adopted to decorate $2 \mathrm{D}$ inorganic nanofillers, we could have good opportunities to improve the flame retardance and significantly reduce the toxic hazards of EP matrix using the synergistic effect.

In addition to the above-mentioned GO, $\mathrm{MoS}_{2}$, etc., boron nitride nanosheets (BNNS) have also been investigated as flame retardants in EP matrix in recent years and the results shows that BNNS could improve the fire resistance of EP to some extent. ${ }^{18,19}$ Fox example, Cai et al. ${ }^{20}$ have adopted polydopamine (PDA) to exfoliate $\mathrm{h}-\mathrm{BN}$, and then prepare h-BN@PDA@ $\mathrm{SnO}_{2}$ for enhancing the fire resistance of EP. The related test results show that incorporation of h-BN@PDA@ $\mathrm{SnO}_{2}$ leads to the reduction of peak heat release rate (PHRR) and total smoke production (TSP) was $41.1 \%$ and $21.6 \%$, respectively, enhancing the flame retardancy of EP. Li et $a l_{.}{ }^{21}$ have synthesized h-BN@PDA@Fe nanohybrids for reducing the fire hazards of EP. And incorporation of 6 wt. $\%$ as-prepared nanohybrids into EP results in the $38.9 \%$ reduction of PHRR and $10 \%$ increase of limiting oxygen index (LOI). More interestingly, some studies show that BNNS can be manipulated to align certain orientation, especially in enhancing the thermal conductivity of EP. ${ }^{22,23}$ However, the study of orientation of BNNS in EP matrix has been rarely reported in flame-retardant fields. Therefore, we select cobalt ferrite nanoparticle $(\mathrm{CFN})$ to decorate BNNS in order to obtain CFN-BNNS nanohybrid with good potential for reducing both the heat hazard and toxic hazard of EP-matrix composites. We also apply an external magnetic field to accommodate the horizontal orientation of CFNBNNS nanohybrids in the EP matrix, hoping to further reduce the fire risk of EP-matrix nanocomposites through the magnetically induced alignment similar to that of CF-BNNS nanofiller. ${ }^{24}$ This paper deals with the effect of CFN-BNNS 
on the flame retardancy of EP based on cone calorimetry test (CCT).

\section{Experimental Methods}

\subsection{Materials used}

Hexagonal boron nitride (h-BN, with the particle of $1-2 \mu \mathrm{m})$ with the purity of $99.9 \%$ and cobalt nitrate hexahydrate $\left(\mathrm{Co}\left(\mathrm{NO}_{3}\right)_{3} \cdot 6 \mathrm{H}_{2} \mathrm{O}\right)$ were supplied from Aladdin (Shanghai, China). Ferrous sulfate heptahydrate $\left(\mathrm{FeSO}_{4} \cdot 7 \mathrm{H}_{2} \mathrm{O}\right)$ was obtained from Tianjin Kermel Chemical Reagent Company (Tianjin, China). Ethylene glycol (EG) was provided by Tianjin Fuyu Fine Chemical Company Limited (Tianjin, China). Ammonia solution was obtained from Luoyang Haohua Chemical Reagent Company Limited (Luoyang, China). Epoxy resin (EP-44 (6101)) was commercially obtained from Zhenjiang Danbao Resin Company Limited (Zhenjiang, China). Deionized water was prepared at our laboratory; and all the regents were used as-received without further purification.

\subsection{Preparation of $C F N-B N N S$ nanohybrid and CFN-BNNS/EP nanocomposites}

BNNS was obtained via thermal exfoliation of h-BN powder at $1000^{\circ}$ for $2 \mathrm{~h} .{ }^{18}$ Briefly, $0.2482 \mathrm{~g}$ of BNNS was dispersed in $40 \mathrm{~mL}$ of deionized water in the ultrasonic bath to obtain a uniform BNNS dispersion. In the meantime, $1 \mathrm{mmol}$ of $\mathrm{Co}\left(\mathrm{NO}_{3}\right)_{2} \cdot 6 \mathrm{H}_{2} \mathrm{O}$ as well as $2 \mathrm{mmol}$ of $\mathrm{FeSO}_{4} \cdot 7 \mathrm{H}_{2} \mathrm{O}$ was dissolved into $40 \mathrm{~mL}$ of the mixture of deionized water and ethylene glycol $\left(\mathrm{V}_{\mathrm{H} 2 \mathrm{O}}: \mathrm{V}_{\mathrm{EG}}=1: 3\right)$; and the resultant mixture was fully stirred for about half an hour at room atmosphere, followed by being added drop by drop into the BNNS dispersion under stirring for $30 \mathrm{~min}$. Then $4 \mathrm{~mL}$ of ammonia was added into the mixed solution with stirring for additional an hour. After completion of stirring, the mixture was transferred to a Teflon autoclave, heated to $180^{\circ} \mathrm{C}$, and maintained there for $24 \mathrm{~h}$. At the end of reaction, transfer the autoclave out of the oven and cool down it in the air. Subsequently, the brown powder was as the crude product was collected. And then the sample was washed with deionized water as well as ethanol for several times, and was dried at $60^{\circ} \mathrm{C}$ in a vacuum oven to afford CFN-BNNS nanohybrid. In the prepared process, the molar ratio of BNNS and $\mathrm{Co}^{2+}$ was controlled in 10:1.
CFN-BNNS/EP nanocomposites were prepared according to the method reported elsewhere. ${ }^{17}$ Briefly, CFN-BNNS nanohybrid was mixed with $40 \mathrm{~g}$ of EP at a mass fraction of $3 \%$ for $10 \mathrm{~min}$ on a ZYMC-200V deaeration mixing mill (Shenzhen Zhongyi Technological Limited Company). Into the resultant viscous mixture was poured $10 \mathrm{~g}$ of curing agent which was mixed for additional $1.5 \mathrm{~min}$. Upon completion of mixing, the solution became rogue with the viscosity of about 937.54 cP measured by Rheometer (Brookfield DV3T, USA), and was transferred into a Teflon mold as fast as possible while a magnetic field was introduced to induce the arrangement of CFN-BNNS nanohybrid in EP matrix, thereby affording desired CFN-BNNS/EP nanocomposite. It is noticeable that the magnetic field was designed from a pair of permanent magnets, which should be remained in rotation in order to the horizontal alignment of the 2D nanofillers. EP, and other EP nanocomposites were also prepared by using the similar way without applying the magnetic field. And the relative preparation process was shown in Fig. 1.

\subsection{Characterization}

The structure of the as-prepared sample was characterized by X-ray diffraction (D8-Advance, Germany), using $\mathrm{CuK} \alpha$ radiation. RM-1000 confocal microscopic Raman spectrometer (Renishaw inVia, UK) was recorded under the excitation of laser at $532 \mathrm{~nm}$, and the morphology of the nanofillers was observed by transmission electron microscopy (JEM-2100, Japan). The freeze-fractured surfaces of various EP-matrix nanocomposites were observed by using a scanning electron microscope (JSM-7001F, Japan). A TGA/DSC3+ thermal analyzer (Mettler Toledo, Switzerland) was deployed for thermogravimetric analysis (TGA) in air and nitrogen condition. And about $5 \mathrm{mg}$ of the asprepared samples were tested for TGA analysis. A TG209F3/Tensor 27 (Netzsch/Bruker, Germany) facility was introduced for thermogravimetricinfrared (TG-IR) analysis of the EP composites in nitrogen atmosphere with heating rate of $10^{\circ} \mathrm{C} / \mathrm{min}$. Moreover, a magnetic measurement system (MPMS3, USA) was used to measure the magnetic hysteresis loops of the EP-matrix nanocomposites at $25^{\circ} \mathrm{C}$ under a magnetic field of $-10,000 \leq H \leq$ 10, 000 Oe. 


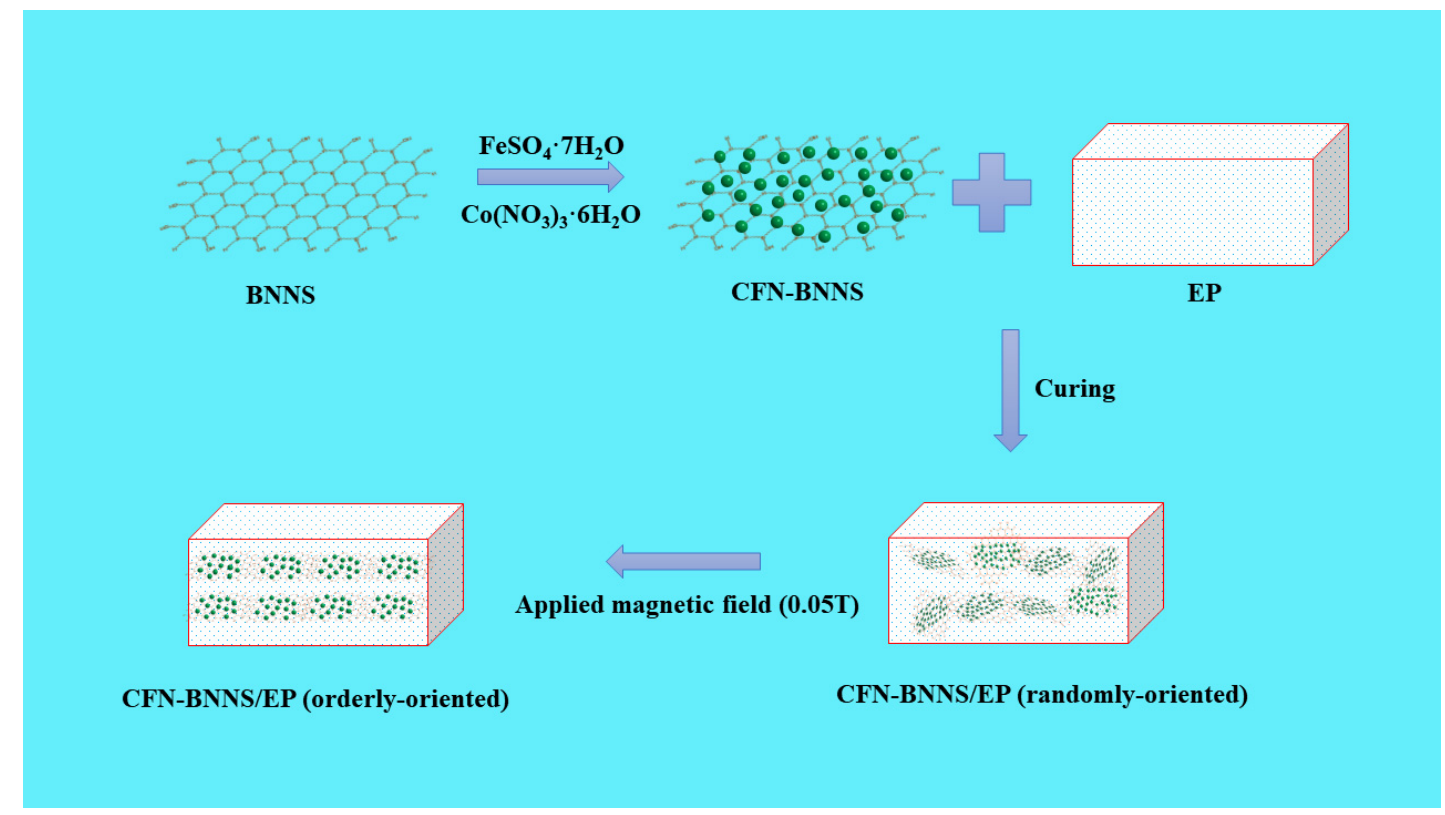

Fig. 1. Schematic diagram for preparation of orderly aligned CF-BNNS/EP nanocomposite.

The flame retardancy of EP and its composites was tested by cone calorimetry in accordance with the procedures of ISO5660, with which the samples with a dimension of $100 \mathrm{~mm} \times 100 \mathrm{~mm} \times 3 \mathrm{~mm}$ were exposed to $35 \mathrm{~kW} \cdot \mathrm{m}^{-2}$ heat flux and tested by Fire Testing Technology (i-Cone, UK). Dynamic mechanical analysis (DMA) from room temperature to $180^{\circ} \mathrm{C}$ was conducted with a rotary rheometer (DHR2, America) in stretching mode at a heating rate of $3{ }^{\circ} \mathrm{C} / \mathrm{min}$.

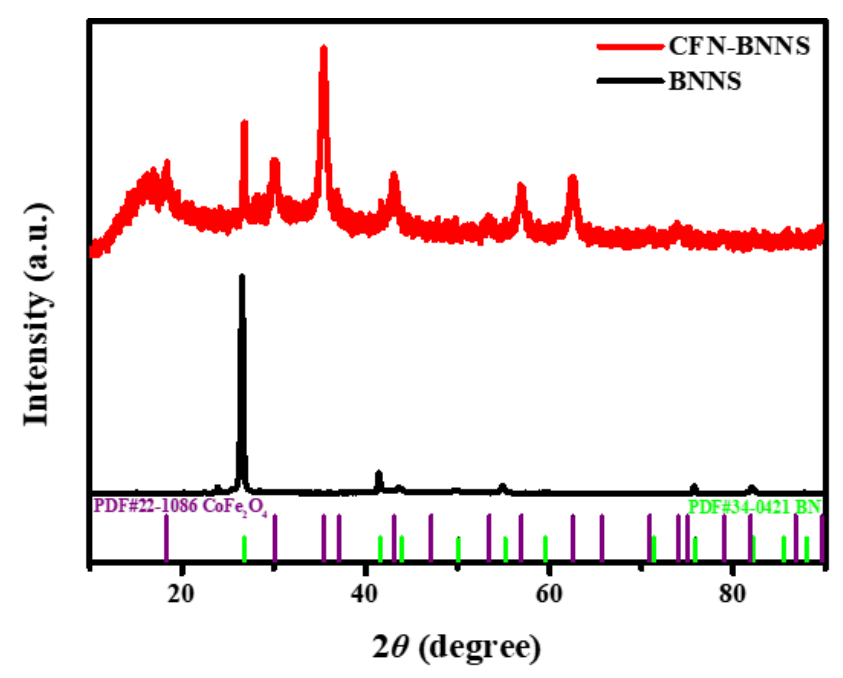

(a)

\section{Results and Discussion}

\subsection{Structure characterization of BNNS and CFN-BNNS nanohybrid}

$\mathrm{X}$-ray diffraction (XRD) is an effective method to characterize the components and stucture of layered-like nanomaterials. The XRD of BNNS and CFN-BNNS nanohybrid were shown in Fig. 2(a). The diffraction peaks of BNNS are consistent with those described in JCPDS No. 34-0421. ${ }^{25}$ In

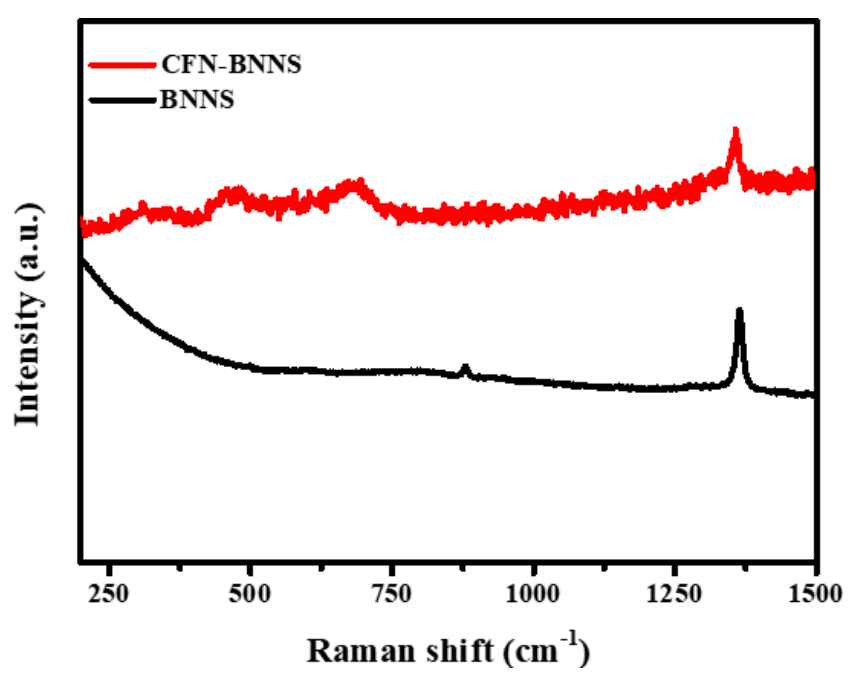

(b)

Fig. 2. XRD patterns and Raman spectra of BNNS and CF-BNNS nanohybrid (a.u. refers to arbitrary unit). 
addition, besides the XRD peaks of BNNS, the CFN-BNNS nanohybrid shows the diffraction peaks of CFN as well (JCPDS No. 22-1086). ${ }^{26}$ Moreover, the diffraction peak of CFN-BNNS centered at around $26.6^{\circ}$ corresponds to the (002) plane of $\mathrm{h}-\mathrm{BN}^{27}$; and the intensity of the (002) plane diffraction peak tends to decline as compared with that of pristine BNNS, possibly due to the encapsulation of BNNS by CFN. ${ }^{11}$ These XRD data provided evidences to the surface decoration of BNNS by CFN with a cubic structure. Corresponding Raman spectra in Fig. 2(b) indicate that BNNS exhibits a strong Raman peak around $1365 \mathrm{~cm}^{-1}$, belong to $E_{2 \mathrm{~g}}$ vibrational mode of $\mathrm{h}-\mathrm{BN}^{28}$; and the new vibrational modes for CFN-BNNS nanomaterial at $309 \mathrm{~cm}^{-1}$, $470 \mathrm{~cm}^{-1}$, and $690 \mathrm{~cm}^{-1}$ belong to $E_{3 \mathrm{~g}}, T_{2 \mathrm{~g}}$ and $A_{2 \mathrm{~g}}$ vibrational modes of CFN. ${ }^{29}$ Moreover, the full width at half-maximum (FWHM) of the $E_{2 \mathrm{~g}}$ vibrational mode of BNNS in CFN-BNNS is broader than that of bare BNNS, which could be attributed to the strong surface scattering after hydrothermal reaction. The Raman spectra combined with relevant XRD data can well prove the successful synthesis of CFN-BNNS hybrid.

Figure 3 shows the transmission electron microscopy (TEM) pictures of BNNS and CFN-BNNS nanohybrid. The exfoliated BNNS consists of thin nanosheet with a diameter of up to $200 \mathrm{~nm}$ (Fig. 3); and CFN-BNNS nanohybrid contains CFN anchored on the BNNS surface [Fig. 3(b)]. Moreover, CFN is dispersed uniformly on BNNS surface, accompanied by a few of aggregates with a diameter of about $10 \mathrm{~nm}$. These TEM images demonstrate that the as-prepared CFN-BNNS nanohybrid does exhibit a hybrid structure, as evidenced by corresponding Raman data and XRD data.
Figure 4 shows the hysteresis loops of BNNS and CFN-BNNS nanohybrid. The CFN-BNNS hybrid with nearly zero magnetic remanence presents an "S"-like hysteresis loop [Fig. 4(A)], which indicates it exhibits super-paramagnetic behavior. The digital camera picture shown in Fig. 4(B) gives further confirmation to such a super-paramagnetic behavior of the CFN-BNNS hybrid. Namely the CFN-BNNS nanohybrid dispersed in water is tightly attached to the magnet. This implies that the as-prepared CFNBNNS nanohybrid might achieve orderly alignment under the externally applied magnetic field, which could be favorable for tuning the orientation of the nanohybrid in EP matrix so as to improve the fire resistance.

\section{2. $S E M$ and $X R D$ characterizations of CFN-BNNS/EP nanocomposites}

The scanning electron microscope (SEM) pictures of the freeze-fractured surfaces of the polymers are presented in Fig. 5. Pure EP has smooth freezefractured surface, and that of BNNS/EP is quite rough [Figs. 5(a) and 5(b)]. The fractured surface of EP containing CFN-BNNS nanohybrid with random distribution has a "honeycomb-like" structure [Fig. 5(c)], and the random-distribution CFNBNNS nanohybrid exhibits good homogeneity among the EP matrix. When an external magnetic field is introduced during the fabrication process of the EP-matrix composites, the CFN-BNNS nanohybrid is well ordered and aligned in the EP matrix [Figs. 5(d)-5(f)]. Particularly, corresponding high magnification SEM images demonstrate that great majority of CFN-BNNS nanohybrid is induced to be oriented horizontally among EP matrix under

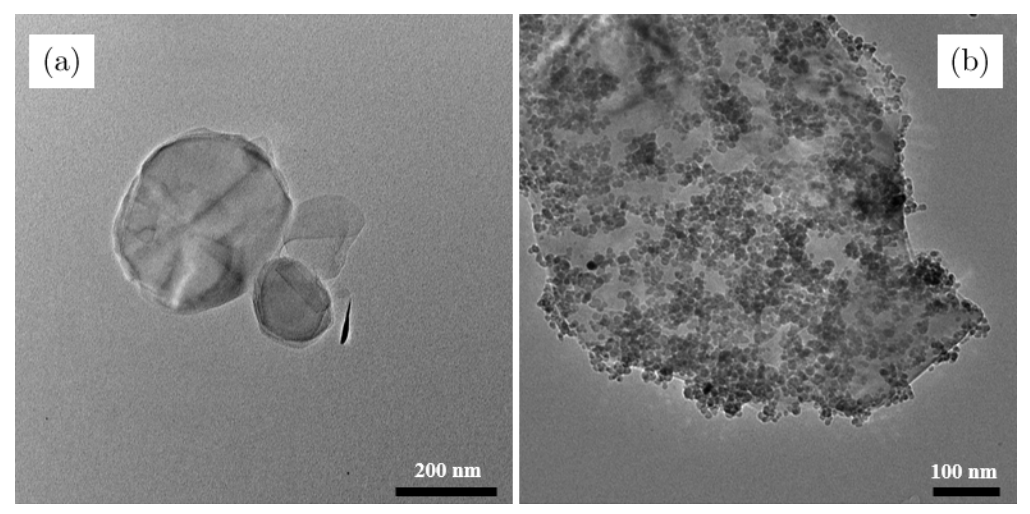

Fig. 3. TEM images of BNNS and CFN-BNNS nanohybrid. 


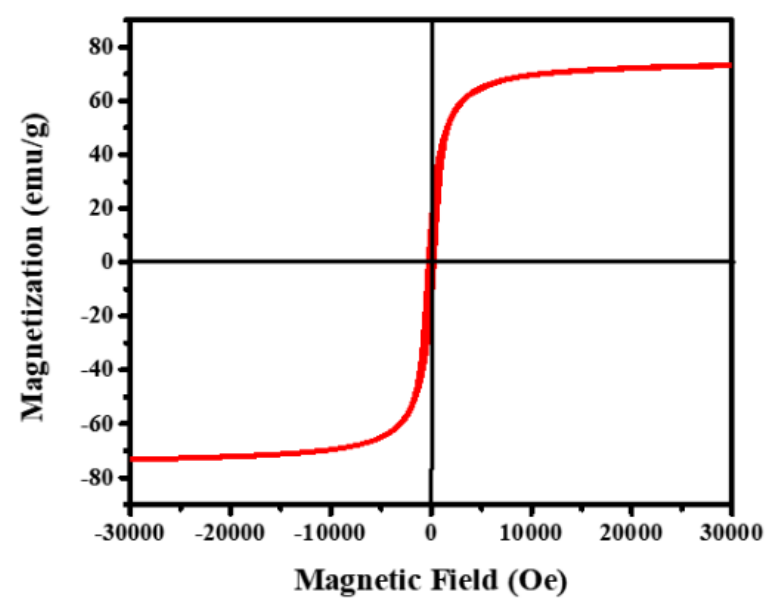

(A)

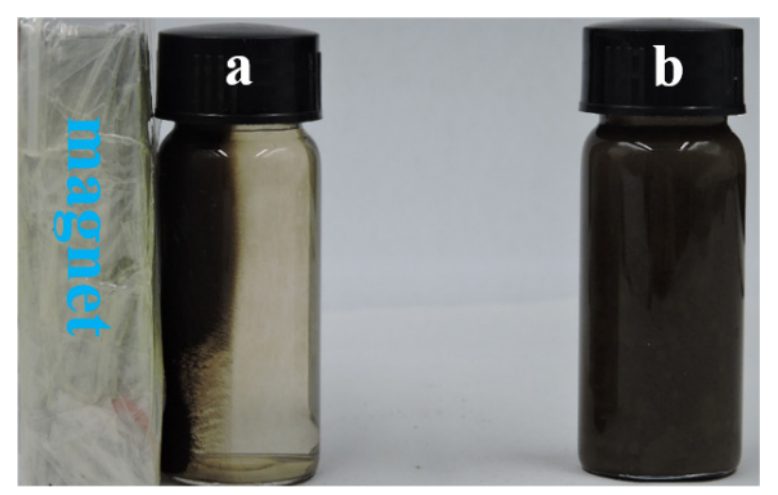

(B)

Fig. 4. (A) Magnetic hysteresis loops of CFN-BNNS nanohybrid; (B) digital camera pictures of CFN-BNNS nanohybrid dispersed in water before (b) and after (a) being exposed to a magnet. the external magnetic field [Figs. 5(g) and 5(h)]. Such an orderly-oriented arrangement of the 2D nanohybrid among EP matrix could contribute to enhancing the shielding effect of BNNS for CFNBNNS nanohybrid, thereby enhancing the fire resistance of the polymer. In addition, the dispersion of CFN-BNNS nanohybrids among matrix was observed by TEM as shown in Fig. 6. It could be observed that the hybrids were dispersed uniformly among EP matrix. It is well known that nanofillers with good dispersion have positive influence on the flame-retardant effect of polymers.

In order to further determine the orientation of CFN-BNNS nanohybrid in the EP matrix, we conducted XRD analysis. The XRD patterns of polymers are presented in Fig. 7 . The broad diffraction peak at around $2 \theta=18^{\circ}$ is assigned to EP. Besides, BNNS/EP and CFN-BNNS/EP nanocomposites with random distribution show a weak peak belong to the (002) plane of BNNS centered around $2 \theta=26.6^{\circ},{ }^{30}$ which implies that the randomly distributed CFN-BNNS nanohybrid exhibits disordered distribution of in the EP. The ordered CFN-BNNS/EP, however, exhibits a much stronger diffraction peak at $26.6^{\circ}$ than the other ones [Fig. 7(b)], which is because the orderly alignment of CFN-BNNS nanohybrid among EP composite under the external magnetic field contributes to enhancing the reflection of (002) plane of BNNS. ${ }^{31,32}$ More importantly, such an orderly oriented nanohybrid could form a large amount of zigzag paths upon
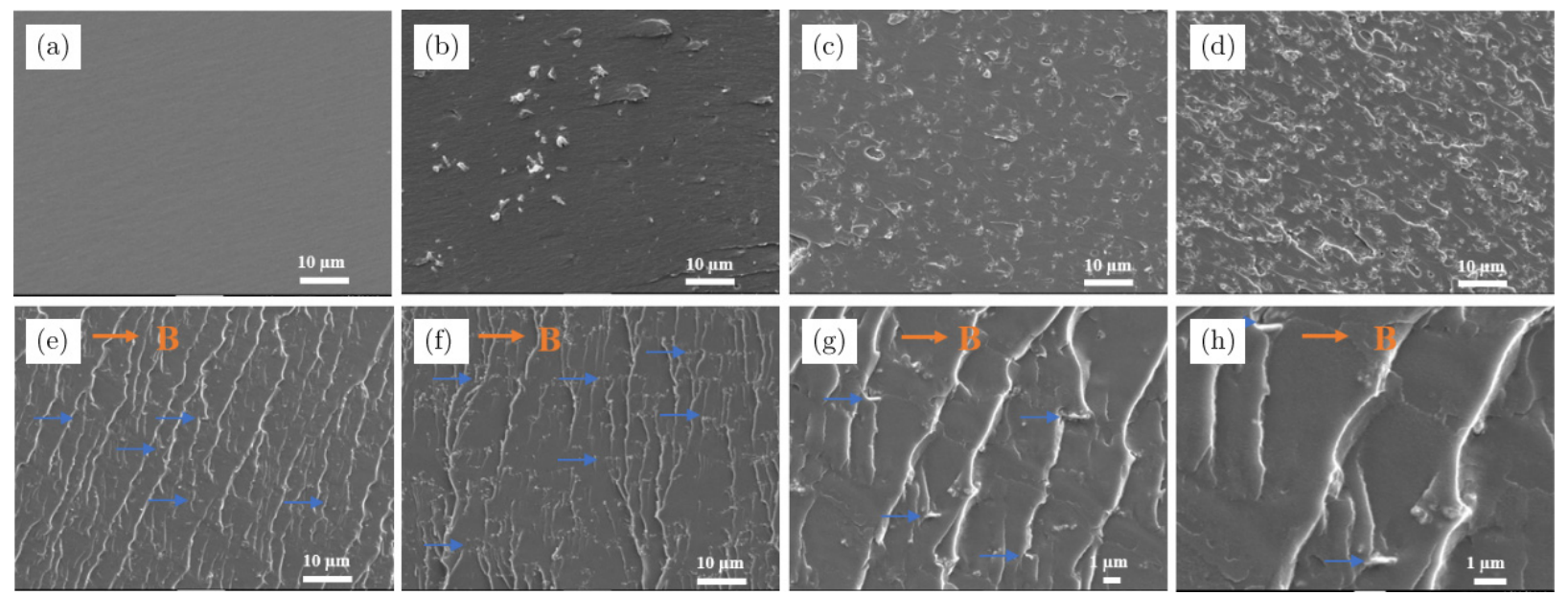

Fig. 5. SEM images of fractured surfaces of (a) pure EP, (b) BNNS/EP, (c) 5 wt.\% randomly oriented CFN-BNNS/EP, (d) 10 wt.\% randomly oriented CF-BNNS/EP, (e) 5 wt.\% orderly oriented CFN-BNNS/EP, (f) 10 wt.\% orderly oriented CFN-BNNS/EP, (g) 5 wt.\% orderly oriented CFN-BNNS/EP at high magnification, and (h) $10 \mathrm{wt} . \%$ orderly oriented CFN-BNNS/EP at high magnification (the direction of the external magnetic field and the ideal orientation of CF-BNNS nanohybrid are indicated by red arrows and blue arrows, respectively) (color online). 


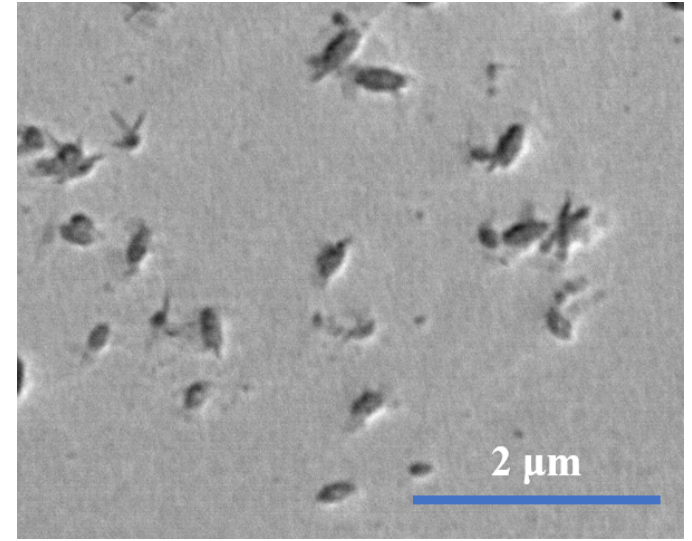

Fig. 6. TEM images of CFN-BNNS/EP nanocomposites.

polymer combustion, thereby leading to improved flame retardancy of EP-matrix nanocomposite.

\subsection{Thermal stability of EP and EP-matrix nanocomposites}

Figure 8 shows the TG and DTG (derivative thermogravimetry) curves of EP and EP composites in the air and nitrogen atmospheres; and Table 1 lists their $T_{\text {onest }}$ (the temperature at which $10 \%$ of weight loss occurs) and $T_{\max }$ (the temperature at which the maximum weight loss occurs). As shown in Figs. 8(a) and 8(c), EP and EP-matrix composites undergo two-stage degradation under air condition, mainly resulting from the molecular chain decomposition and the oxidation of residual $\operatorname{chars}^{17}$; and the $T_{\text {onest }}$ value of BNNS/EP is a little lower, compared with that of pristine EP, possibly due to the high thermal conductivity of BNNS and the agglomeration of BNNS among EP matrix. Besides, the $T_{\text {onest }}$ value of CFN-BNNS/EP nanocomposite is lower, compared to that of BNNS/EP, indicating that the incorporation of both the randomly distributed and the orderly-oriented CFN-BNNS nanohybrids results in accelerating the decomposition of EP molecular chains at the early stage, due to the catalytic effect of CFN. Moreover, the $T_{\max }$ value of the EP-matrix nanocomposites filled with either randomly aligned CFN-BNNS nanofiller or orderly oriented CFN-BNNS nanofiller is higher than that of BNNS/EP composite, likely (a)

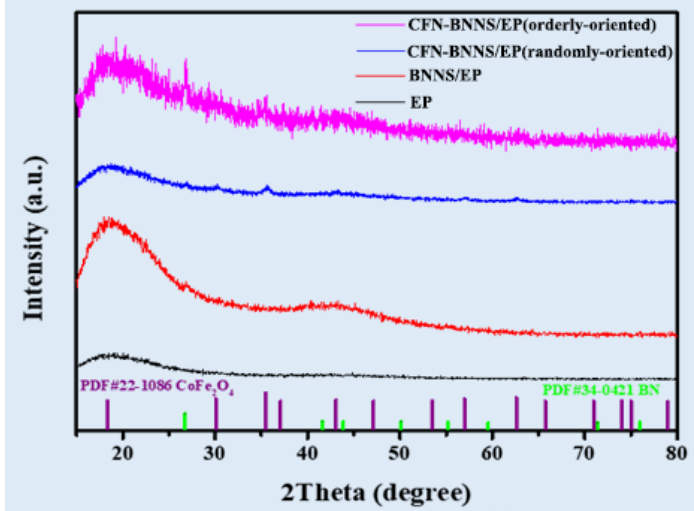

(b)

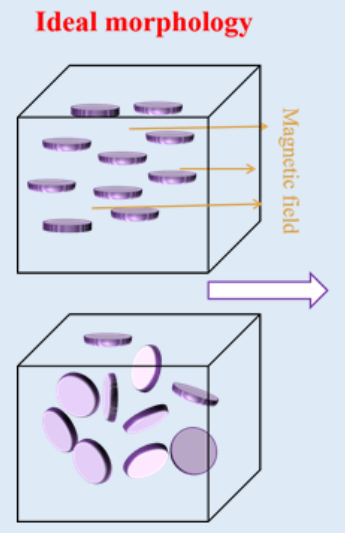

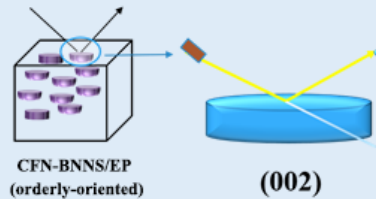
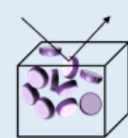

CFN-BNNS/EP (randomly-oriented)

(c)
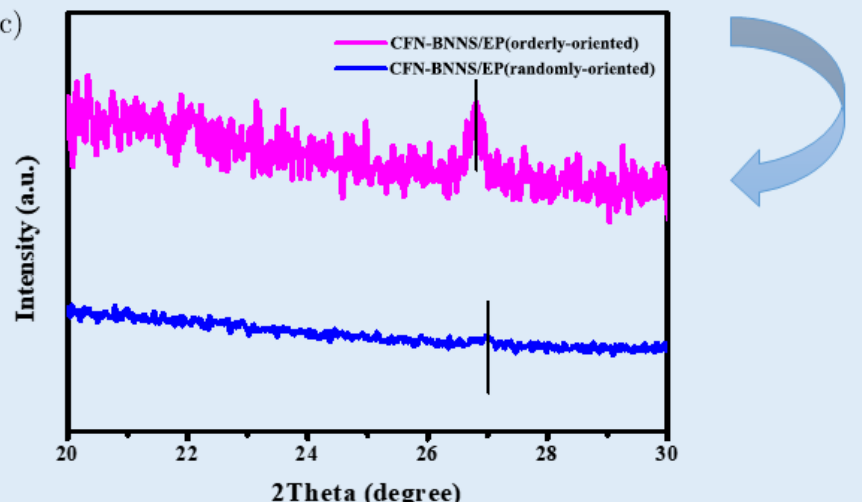

Fig. 7. (a) XRD patterns of EP, BNNS/EP, CFN-BNNS/EP (randomly oriented) and CFN-BNNS/EP (orderly oriented) in $2 \theta$ range of $15-80^{\circ}$; (b) illustration of effect of orientation of CFN-BNNS nanohybrid on XRD pattern; (c) selected part of XRD patterns in $2 \theta$ range of $20-30^{\circ}$. 


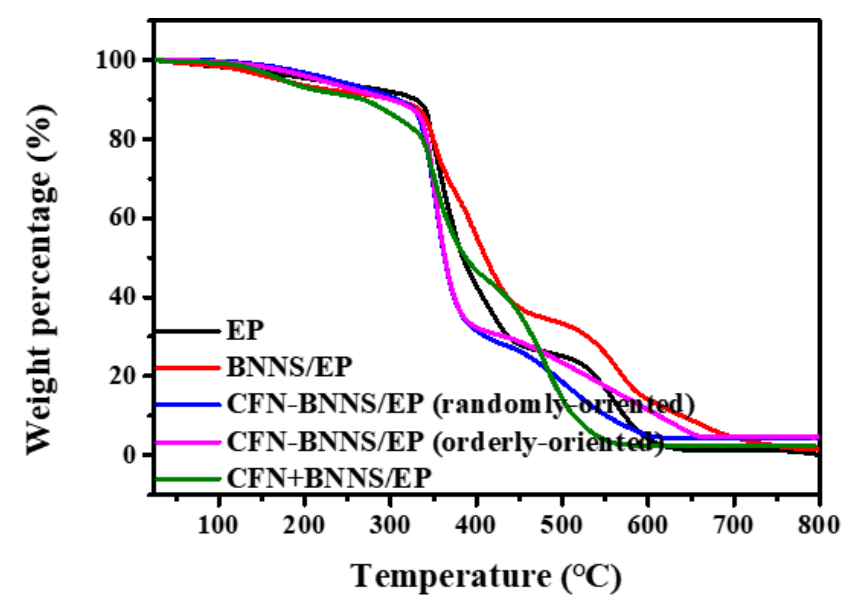

(a)

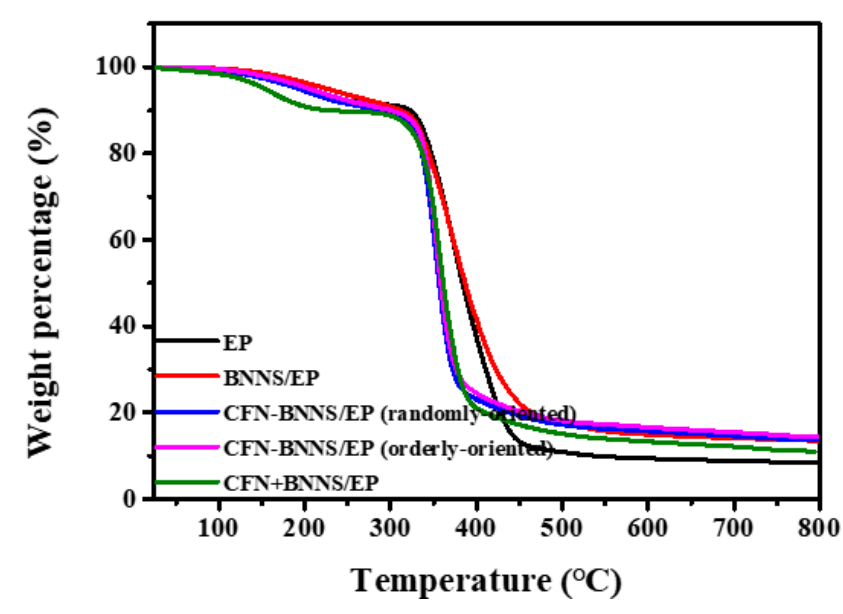

(c)

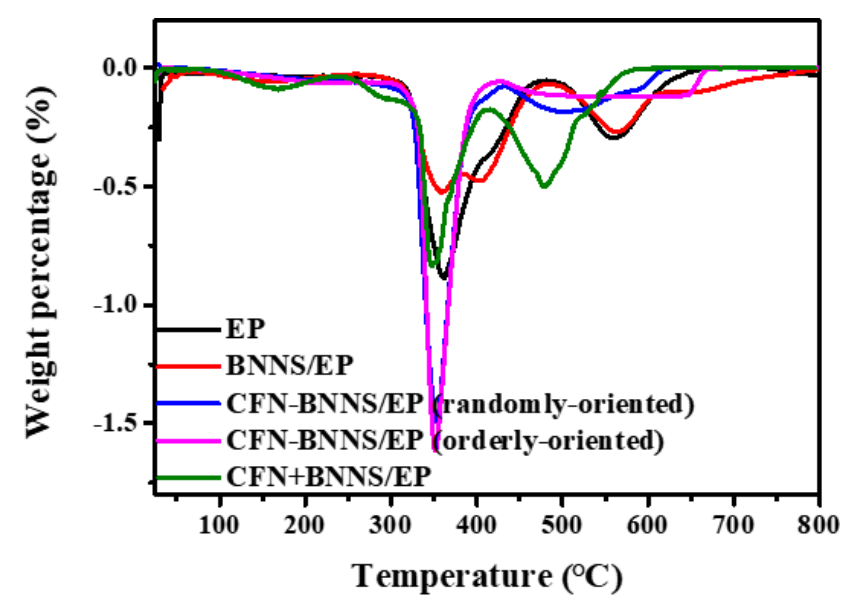

(b)

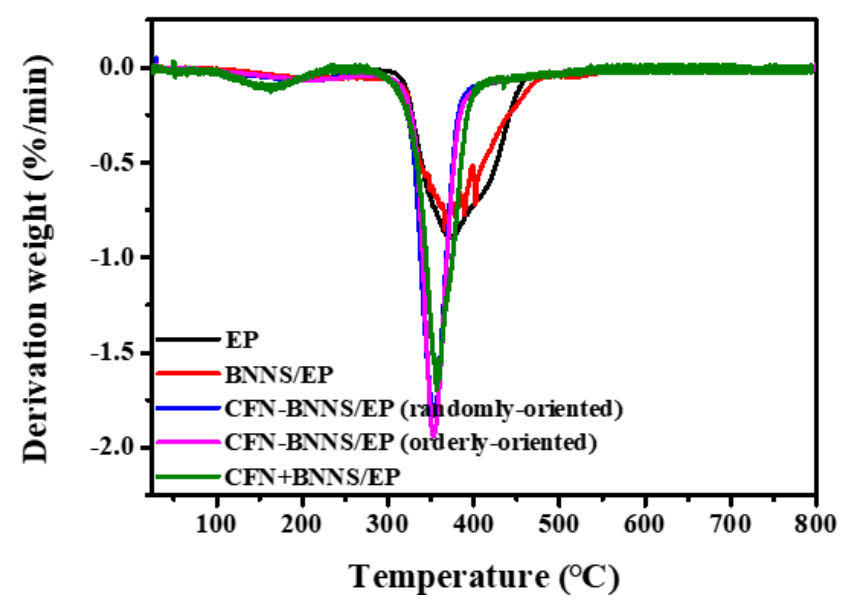

(d)

Fig. 8. TGA curves (a) and (b) and DTG curves (c) and (d) of EP and its nanocomposites under air (a) and (c) and nitrogen (b) and (d) atmospheres.

attributing to the charring function of $\mathrm{CFN}$ in CFN-BNNS nanohybrid. Such a charring function of CFN in CFN-BNNS nanohybrid is also supported by the finding that the EP-matrix composites filled with random and ordered CFN-BNNS nanofillers provide a residual char yield of $4.4 \mathrm{wt} . \%$ and $4.5 \mathrm{wt} . \%$ at $800^{\circ} \mathrm{C}$. This phenomenon could be understood that the transition metal element could usually catalyze the decomposed components into more protective char. $^{33}$ Namely, the two types of CFN-BNNS nanofillers can both allow char residues to be anchored on the surface of polymer.

In nitrogen atmosphere, BNNS/EP and CFN-BNNS/EP nanocomposites have relatively

Table 1. Thermal analysis data of EP and EP-matrix nanocomposites under air and nitrogen atmospheres.

\begin{tabular}{|c|c|c|c|c|c|c|}
\hline \multirow[b]{2}{*}{ Samples } & \multicolumn{2}{|c|}{$T_{\text {onest }}\left({ }^{\circ} \mathrm{C}\right)$} & \multicolumn{2}{|c|}{$T_{\max }\left({ }^{\circ} \mathrm{C}\right)$} & \multicolumn{2}{|c|}{ Residue at $800^{\circ} \mathrm{C}$ (wt.\%) } \\
\hline & $\mathrm{N}_{2}$ & Air & $\mathrm{N}_{2}$ & Air & $\mathrm{N}_{2}$ & Air \\
\hline $\mathrm{EP}$ & 322.2 & 329.5 & 372.8 & 361.2 & 8.5 & 0.2 \\
\hline $\mathrm{BNNS} / \mathrm{EP}$ & 311.5 & 304.7 & 366.8 & 347.8 & 13.5 & 1.4 \\
\hline $\mathrm{BNNS}+\mathrm{CFN} / \mathrm{EP}$ & 224.2 & 267.8 & 356.3 & 347.7 & 11.0 & 2.3 \\
\hline Disordered CFN-BNNS/EP & 291.8 & 301.1 & 352.6 & 353.2 & 13.5 & 4.4 \\
\hline Orderly aligned CFN-BNNS/EP & 299.9 & 300.2 & 353.1 & 351.4 & 14.4 & 4.5 \\
\hline
\end{tabular}


low $T_{\text {onest }}$ values, which indicates that BNNS with a higher thermal conductivity and CFN with catalytic charring property facilitates the initial decomposition of the EP-matrix nanocomposites at a low temperature in nitrogen atmosphere [Figs. 8(b) and $8(\mathrm{~d})]$. As to $T_{\max }$, it could be found that CFN-BNNS/EP both have lower values than those of pure EP as well as EP filled with BNNS. The one potential reason could be the strong catalytic effect of ferrite, promoting the cross-linking and charring reaction at the early stage. The second one may be because that the char residue of CFN-BNNS/EP generated in the first stage is unstable with the cracking, among which the remainders were mainly aliphatic fragments on the condensed phase. ${ }^{34}$ Usually, char residue yield is considered to be an important parameter to evaluate the thermal stability of materials, which could play an important role in blocking the thermal diffusion. In the meantime, the EP-matrix nanocomposites filled with various flame retardants provide enhanced char yields as compared with the EP matrix.

As a comparison, the CFN+BNNS flame retardant was introduced into EP, for evaluating whether the nanohybrid is better or not. And shown in Table $1, \mathrm{CFN}+\mathrm{BNNS} / \mathrm{EP}$ has lower $T_{\text {onest }}$ values than CFN-BNNS/EP, exhibiting the earlier decomposition of CFN+BNNS/EP in $\mathrm{N}_{2}$ and air condition. Besides, the char residue of $\mathrm{CFN}+\mathrm{BNNS} / \mathrm{EP}$ in $\mathrm{N}_{2}$ and air was less than CFNBNNS/EP, indicating that the CFN-BNNS has better char-formation ability, which is more superior than $\mathrm{CFN}+\mathrm{BNNS}$ flame retardant. Hence, it is concluded that CFN-BNNS hybrids is more useful for EP matrix, which is suitable for enhancing the fire resistance of the polymers.

\subsection{Fire hazard evaluation by cone calorimetry test}

Cone calorimetry test, CCT in short, is a powerful tool to evaluate the fire risk of polymers, and it can simulate real combustion environment. Figure 9(a) and Table 2 present the peak heat release rate $(P H R R)$, peak smoke production release $(P S P R)$, time to $P H R R\left(t_{P H R R}\right)$, total smoke rate $(T S R)$, time to ignition $(T T I)$ and fire performance index $(F P I)$, and fire growth index $(F G I)$ determined by CCT. Pure EP has the highest PHRR value of $1128.7 \mathrm{~kW} \cdot \mathrm{m}^{-2}$, showing a high flammability. The introduction of BNNS leads to a reduction of $P H R R$ by $22.1 \%$. When CFN-BNNS nanohybrids, whether randomly aligned one or orderly oriented one, are used as the flame-retardant additives of EP, the PHRR values of the resultant CFN-BNNS/EP nanocomposites are further reduced, resulting from the nanobarrier effect of BNNS in combination with the catalytic charring property of CFN. Interestingly, the incorporation of $3 \mathrm{wt} . \%$ of randomly aligned CFN-BNNS nanohybrid reduces the PHRR value of the EP-matrix nanocomposite by $32.2 \%$; and the incorporation of the orderly oriented CFNBNNS nanohybrid at the same mass fraction reduces the PHRR value of the EP-matrix nanocomposite by $44.1 \%$. This indicates that the CFN-BNNS nanohybrid with ordered orientation among the EP is more beneficial to reducing the fire hazard of EP. Besides, the EP-matrix nanocomposite filled with the orderly aligned CFN-BNNS nanohybrid exhibits the maximum $t_{\mathrm{PHRR}}$ value and $T T I$ value among various tested nanocomposites, which is significant for rescuing fire trapped people and for reducing the fire hazard of EP as well. This implies that the CFNBNNS nanohybrid with horizontal orientation in the EP can effectively shield and reflect the heat and oxygen from fire zone and prevent them from permeating into the inner polymer matrix during combustion, thereby slow down the growth of fierce fire. However, the enhancement of fire resistance of oriented CFN-BNNS has not meet the expected performance, compared with that of the random composites. The phenomenon is mainly because the ordered structure of CFN-BNNS may tend to be damaged by the micro-flow of polymer melt during combustion.

Figures $9(\mathrm{~b})$ and $9(\mathrm{c})$ show the combustion curves (e.g., $S P R$, and carbon monoxide production $(C O P)$ of the EP nanocomposites. The incorporation of the ordered CFN-BNNS nanohybrid in the EP matrix results in the lowest $P S P R$ value of $0.188 \mathrm{~m}^{2} \cdot \mathrm{s}^{-1}$ (decreased by $41.3 \%$ as compared with that of pritine EP $\left.\left(0.320 \mathrm{~m}^{2} \cdot \mathrm{s}^{-1}\right)\right)$, which means the orderly aligned CFN-BNNS nanohybrid exhibits excellent smokesuppressing performance. Similarly, the orderly aligned CFN-BNNS nanohybrid also contributes to reducing the release of toxic $\mathrm{CO}$ during $\mathrm{EP}$ combustion, which is because the highly ordered layered-structure nanofiller exhibits enhanced barrier effect and shielding effect. 


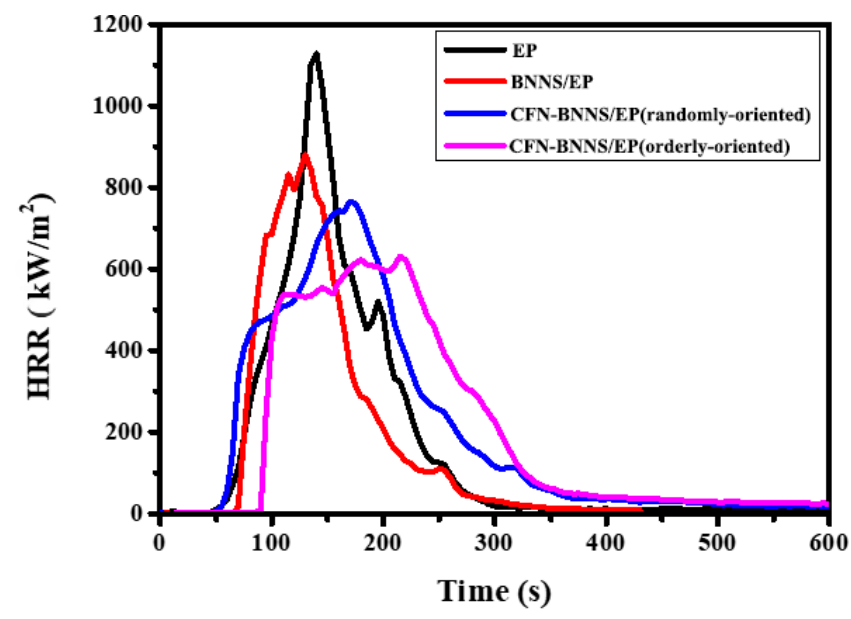

(a)

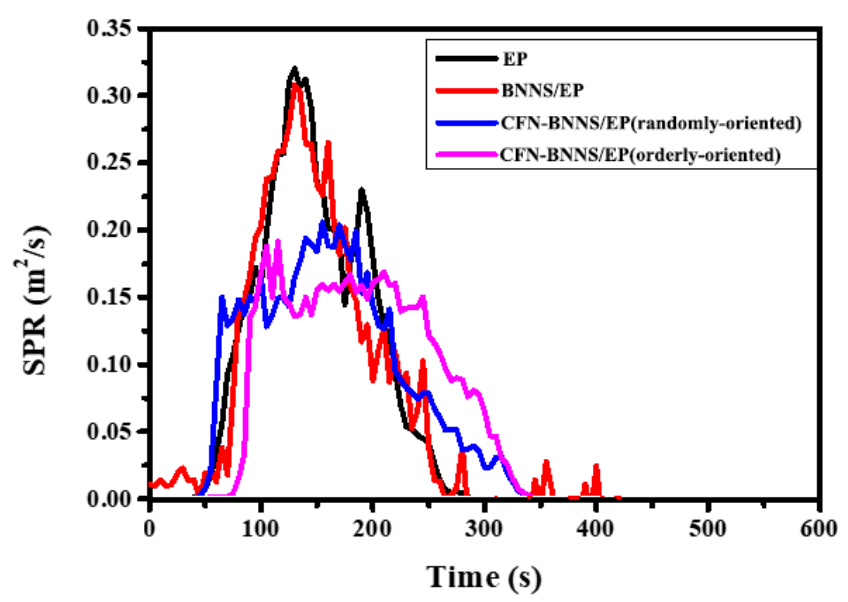

(b)

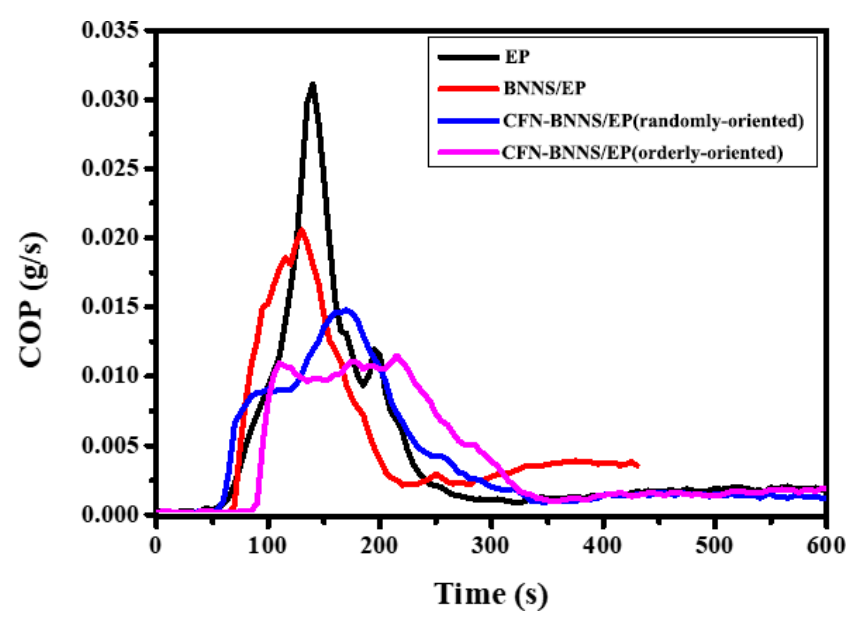

(c)

Fig. 9. (a) HRR, (b) SPR, and (c) COP curves of EP and EP-matrix nanocomposites obtained from the cone calorimetry tests.

Table 2. Combustion parameters of EP and EP-matrix nanocomposites.

\begin{tabular}{lcccccccc}
\hline Sample & $\begin{array}{c}P H R R \\
T T I(\mathrm{~s})\end{array}$ & $\begin{array}{c}C O P \\
\left(\mathrm{~kW} \cdot \mathrm{m}^{-2}\right)\end{array}$ & $\begin{array}{c}\text { PSPR } \\
t_{P H R R}(\mathrm{~s})\end{array}$ & $\begin{array}{c}\text { TSR } \\
\left(\mathrm{g} \cdot \mathrm{s}^{-1}\right)\end{array}$ & $\begin{array}{c}F G I \\
\left(\mathrm{~m}^{2} \cdot \mathrm{s}^{-1}\right)\end{array}$ & $\begin{array}{c}\left.F \mathrm{~m}^{2} \cdot \mathrm{m}^{-2}\right) \\
\left(\mathrm{kW} \cdot \mathrm{m}^{-2} \cdot \mathrm{s}^{-1}\right) \\
\left(\mathrm{kW} \mathrm{W}^{-1} \cdot \mathrm{m}^{2} \cdot \mathrm{s}\right)\end{array}$ \\
\hline EP & 87 & 1128.7 & 140 & 0.031 & 0.320 & 3744.6 & 8.06 & 0.077 \\
BNNS/EP & 73 & 879.8 & 130 & 0.021 & 0.308 & 3587.2 & 6.77 & 0.083 \\
Disordered CFN-BNNS/EP & 70 & 765.5 & 170 & 0.015 & 0.206 & 3545.5 & 4.50 & 0.091 \\
Orderly aligned CFN-BNNS/EP & 82 & 631.3 & 215 & 0.011 & 0.188 & 3474.0 & 2.94 & 0.130 \\
\hline
\end{tabular}

\subsection{Analysis of flame-retardant mechanism}

\subsubsection{Condensed phase analysis}

Normally, the analysis of the morphology and structure of residual chars, i.e., the condensed phase, can provide information about flame retardancy mechanism. Figure 10 gives the digital camera pictures and SEM pictures of the residual chars for EP and its composites after cone calorimetry test. Pristine EP presents little residue after CCT [Fig. 10(a)], which well corresponds to its poor flame retardancy. The introduction of the nanofillers results in an obvious increase in the amount of char residues; and in particularly, the incorporation of the CFN-BNNS nanohybrids results in 


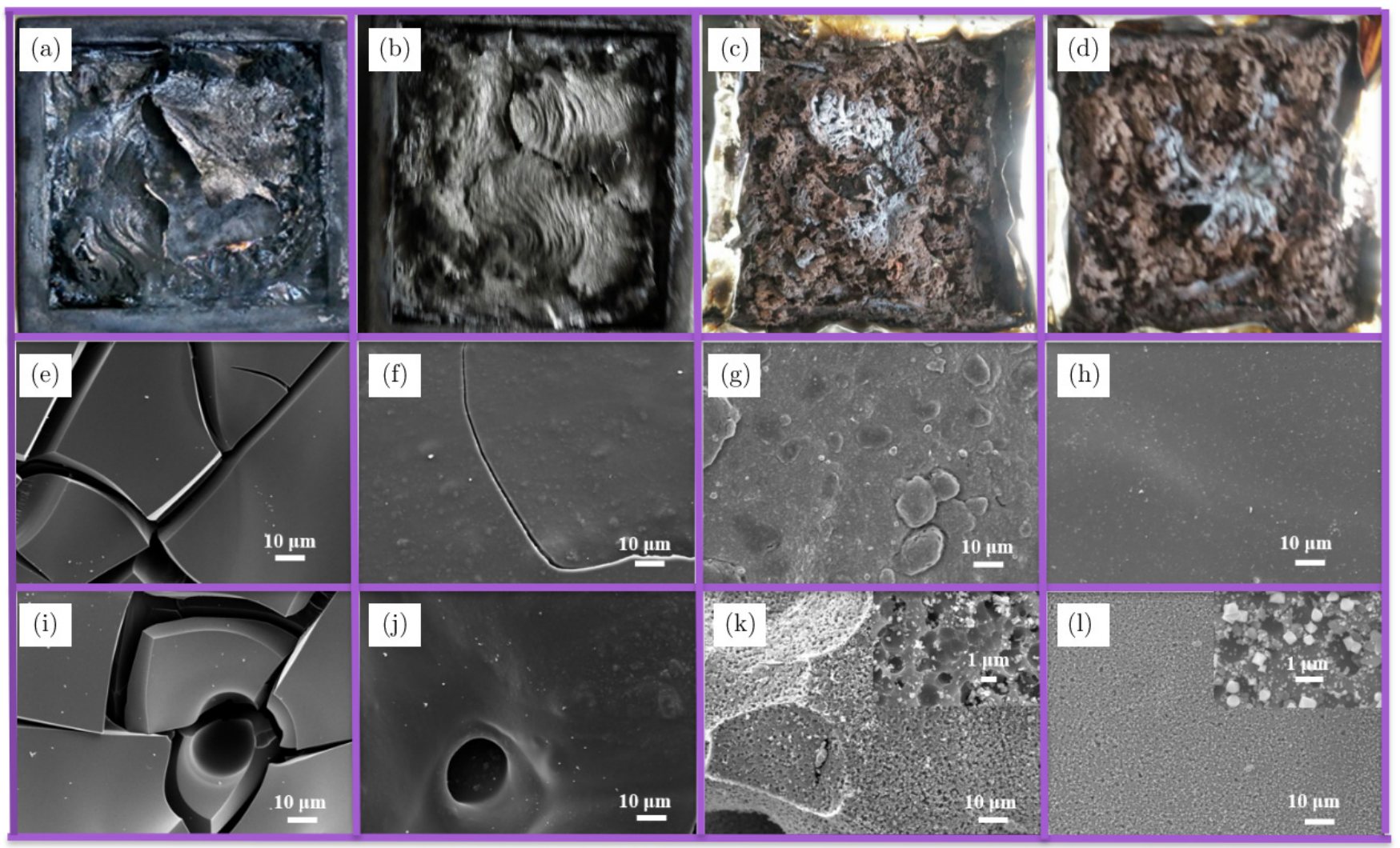

Fig. 10. Digital camera photos of the char residues of (a) EP, (b) BNNS/EP, (c) randomly oriented CFN-BNNS/EP and (d) orderly oriented CFN-BNNS/EP as well as SEM images of the outer (e), (f), (g), (k) and inner surfaces (i)-(l) of char residues of EP (e) and (i), BNNS/EP (f) and (j), randomly oriented CFN-BNNS/EP (g) and (k), and orderly oriented CF-BNNS/EP (h) and (l) after cone calorimetry tests.

significantly increased char layer [Figs. 10(c) and 10(d)]. Moreover, obvious cracks and pores for EP are appeared [Figs. 10(e) and 10(i)] and BNNS/ EP [Figs. 10(f) and 10(j)] after the CCT; but continuous and compact char layers are observed for CFN-BNNS/EP nanocomposites thereafter. As seen in corresponding digital camera pictures and SEM images, the outer char of the EP-matrix nanocomposites filled with the two types of CFNBNNS nanofillers show similar morphology with robust char layer. As for the inner char, the char residue of CFN-BNNS/EP with different orientation exhibits a little difference, and the oriented CFN-BNNS/EP presents more denser morphology, contributing to enhance the barrier effect. However, the randomly aligned CFN-BNNS/EP nanocomposite generates residual char with bigger holes [Figs. 10(g) and 10(k)], possibly due to the weaker shielding effect of the randomly aligned CFN-BNNS nanohybrid in association with the release of some organic pyrolysis products. Different from the randomly aligned CFN-BNNS/EP nanocomposite, EP filled with orderly aligned CFN-BNNS nanofiller produces a continuous and dense char [Figs. 10(h) and 10(l)], attributing to the enhanced physical barrier effect of the ordered CFN-BNNS nanofiller in EP matrix.

The chars of EP and its nanocomposites were further analyzed by Raman spectroscopy in order to evaluate the graphitization degree and stability of the char residues. As shown in Fig. 11, EP and EPmatrix nanocomposites exhibit two prominent Raman peaks around $1362 \mathrm{~cm}^{-1}$ and $1600 \mathrm{~cm}^{-1}$, corresponding to the $\mathrm{D}$ band and $\mathrm{G}$ band of graphite, respectively. Normally, the intensity ratio of the $\mathrm{D}$ band and $\mathrm{G}$ band, i.e., $I_{\mathrm{D}} / I_{\mathrm{G}}$, can be cited to evaluate the graphitization degree of the residual chars. Usually, the lower value of $I_{\mathrm{D}} / I_{\mathrm{G}}$ means the higher graphitization degree. And the higher graphitization degree of the residual char is corresponding to the higher thermal oxidation resistance, contributing to enhance the fire resistance. ${ }^{35}$ The $I_{\mathrm{D}} / I_{\mathrm{G}}$ values of pure EP and EP filled with orderly aligned CFN-BNNS nanofiller are 3.44 and 1.69, 


\section{Q. Zhang et al.}

respectively, which indicates that the condensed phase of the latter exhibits the highest degree of graphitization upon CCT. ${ }^{18}$ The residual char with higher degree of graphitization can form stable and continuous char layer as insulation barrier, thereby well inhibiting the degradation of the inner EP matrix and enhancing the fire resistance ability.

Figure 12 presents the XRD patterns and FT-IR spectra of char residues of EP and its composites. The residual char of EP presents a broadened XRD peak at $2 \theta=23^{\circ}$ [Fig. 12(a)], and this diffraction peak is assigned to the (002) plane of graphite. ${ }^{8}$ However, the diffraction peak of graphite of EP composites has not appeared, and the main cause is due to the higher intensity of the inorganic nanofillers which results in hiding the peak of graphite. Besides, combined with Raman spectra, the other cause is likely that the degree of graphitization of EP composites was increased induced by the catalytic effect of BNNS and CFN. The XRD pattern of the residual char of BNNS/EP is consistent with that of BNNS (JCPDS card No. 34-0421), which means that the BNNS incorporated in the EP matrix can well retained in the char layer. Besides, a new weak peak centered around $2 \theta=27.9^{\circ}$ is assigned to the (010) plane of $\mathrm{B}(\mathrm{OH})_{3},{ }^{36}$ which

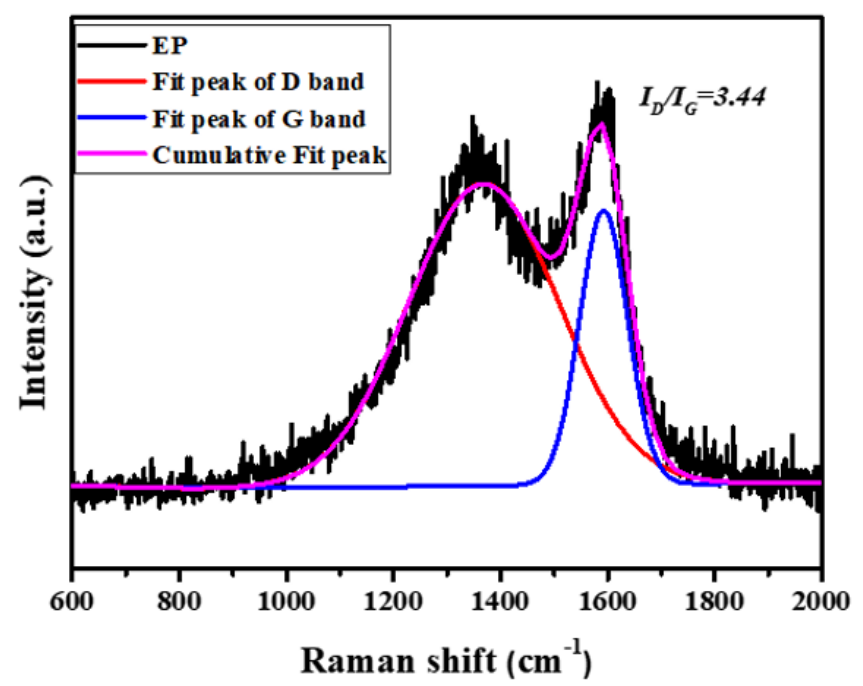

(a)

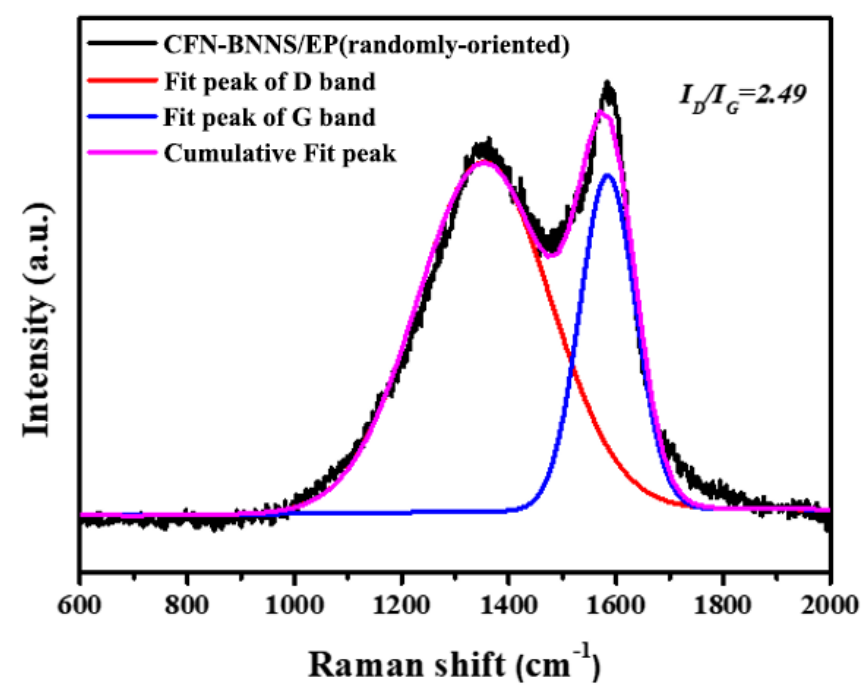

(c)

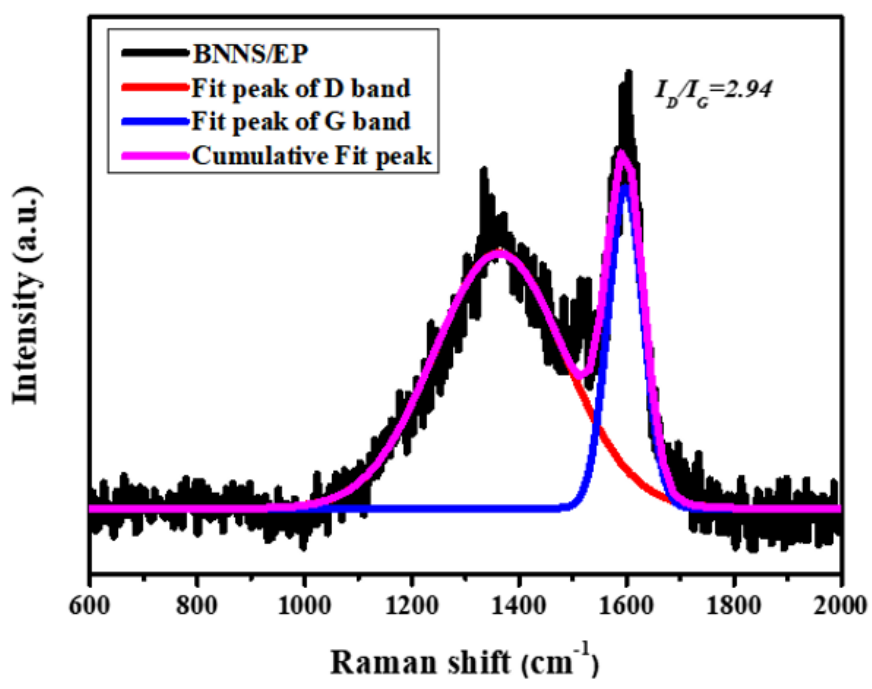

(b)

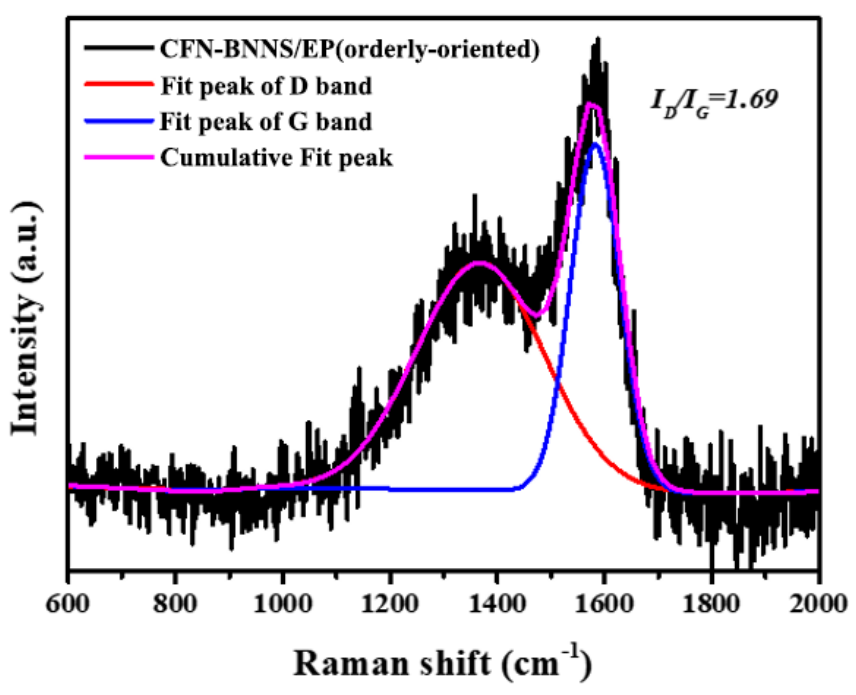

(d)

Fig. 11. Raman spectra of char residues of EP-matrix nanocomposites: (a) EP, (b) BNNS/EP, (c) randomly oriented CFN-BNNS/ EP, and (d) orderly oriented CFN-BNNS/EP. 


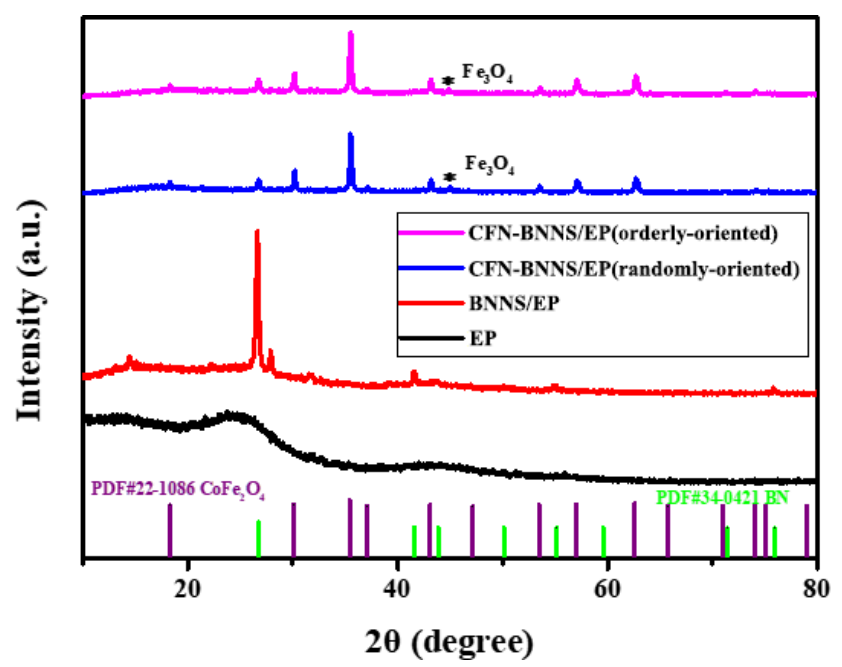

(a)

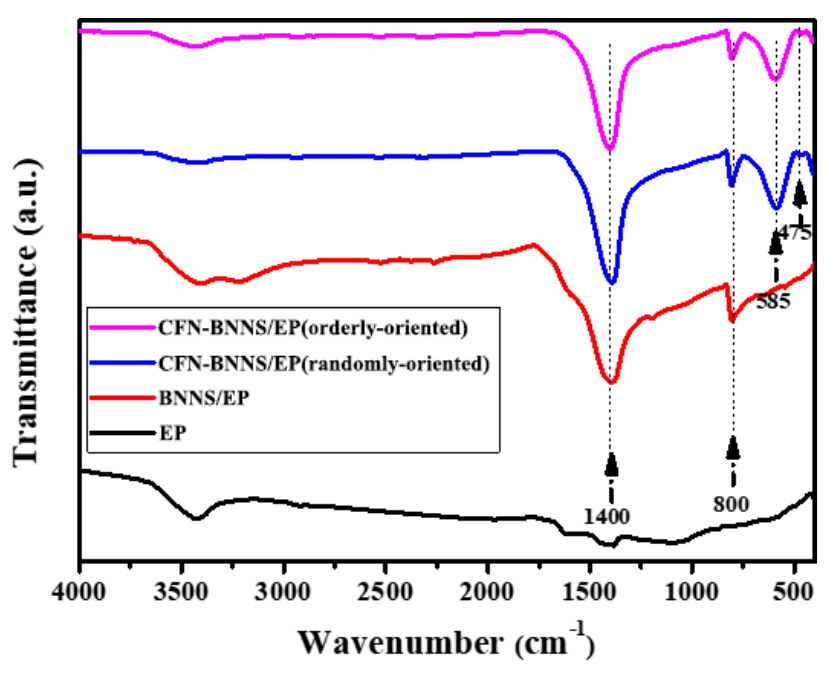

(b)

Fig. 12. (a) XRD patterns and (b) FT-IR spectra of char residues for EP and its nanocomposites after cone calorimeter tests.

indicates that the BNNS filler is partly oxidized during the fierce combustion process. Moreover, aside from the XRD signals of BNNS and CFN, CFN-BNNS/EP nanocomposite exhibits the XRD signal of $\mathrm{Fe}_{3} \mathrm{O}_{4}$, which is due to decomposition of CFN generating ferrite and colt species. The ferrite species are retained in the condensed phase to play a significant role in promoting the decomposition of EP matrix affording protective char layer. In the meantime, the cobalt species can catalyze the oxidation of $\mathrm{CO}$ and reduce the toxic hazards. And the FT-IR spectra of the residual char is shown in Fig. 11(b), and the band of $\mathrm{B}-\mathrm{N}$ and $\mathrm{Fe}-\mathrm{O}$ has been appeared at around $1400 \mathrm{~cm}^{-1}$ and $475 \mathrm{~cm}^{-1},{ }^{17}$ which gives more evidence for XRD.

\subsubsection{Gaseous phase analysis}

Various pyrolysis products such as toxic gases and organic combustible gases are generated during combustion, and they can be detected by TG-IR technique. Figure 13 shows the major pyrolysis gases for EP and EP-matrix nanocomposites upon the maximum decomposition. The FT-IR signals at $2950 \mathrm{~cm}^{-1}, 1510-1460 \mathrm{~cm}^{-1}, 2182 \mathrm{~cm}^{-1}, 2362 \mathrm{~cm}^{-1}$, $3600-3700 \mathrm{~cm}^{-1}$, and $1750 \mathrm{~cm}^{-1}$ are assigned to hydrocarbons, aromatic-containing compounds, $\mathrm{CO}, \mathrm{CO}_{2}$, water, and carbonyl-containing compounds, respectively. ${ }^{37}$ Besides, compared with pure EP, EP-matrix nanocomposites exhibit obviously reduced absorbance of combustible products, aromatic-containing compounds as well as hydrocarbons. Particularly, the flammable products of CFN-BNNS/EP have the lowest absorbance intensity, resulting from the so-called "labyrinth effect" of BNNS with layered structure and the catalytic charring effect of CFN. Moreover, the toxic products of CFN-BNNS/EP nanocomposite, especially $\mathrm{CO}$, are also reduced as compared with that of neat EP. However, the trend of $\mathrm{CO}$ curves from TG-IR is not the same as that of CCT. It is considered that the main cause of the difference of measurement between TG-IR and CCT. TG was microcosmic with the amount of $5 \mathrm{mg} 3 \mathrm{D}$ heating while CCT is macroscopic with fire heating. These TG-IR data well correspond to the finding that the CFN-BNNS/EP nanocomposite exhibits greatly decreased PHRR value and toxic hazards as compared with the EP matrix.

Based on the analyses of the condensed phases and gases phases, Fig. 14 schematically shows the flame retardancy mechanism of CFN-BNNS nanofiller among EP matrix. On the one hand, BNNS with nanolayer structure as a nanobarrier can prevent oxygen and heat from entering into internal polymer during combustion; and the CFN-BNNS nanofiller with ordered orientation among the EP matrix can more effectively inhibit the transfer of heat and oxygen. On the other hand, CFN can catalyze the degradation of EP to afford protected chars anchored on the surface of polymer; and it can also be decomposed to generate ferrite species as well as cobalt species. The ferrite species can promote the polymer degradation to afford additional 


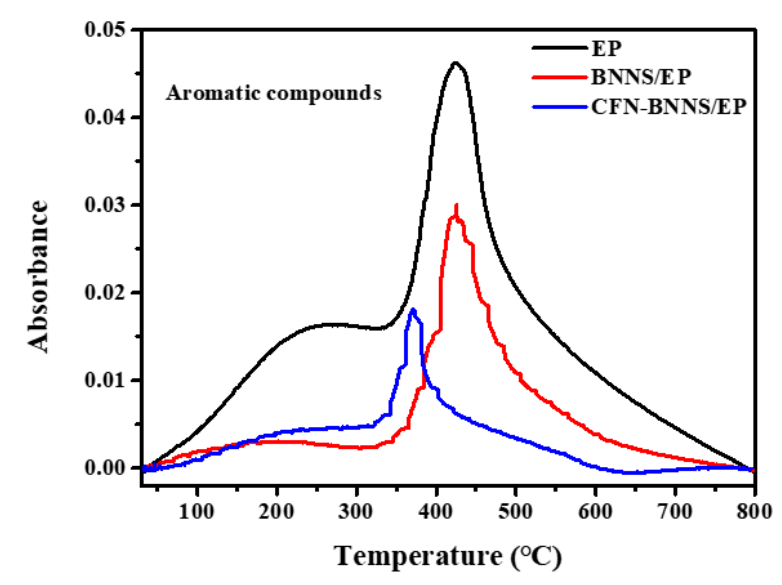

(a)

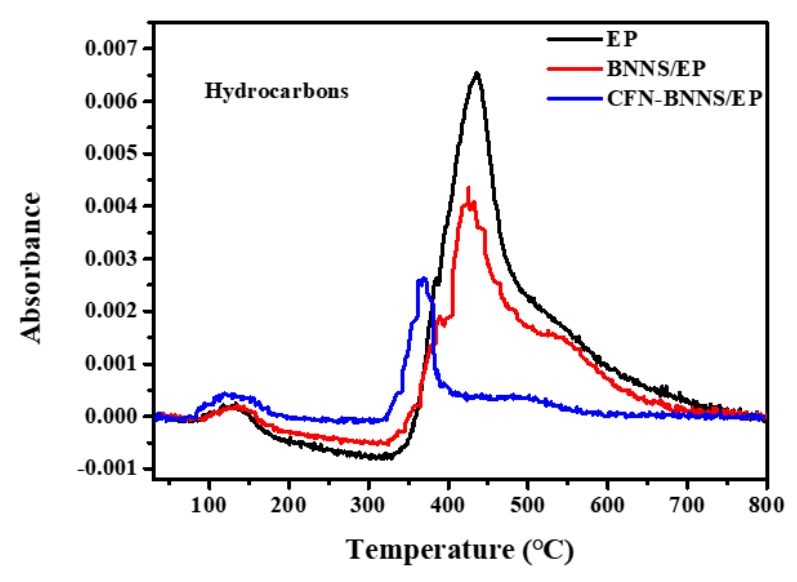

(c)

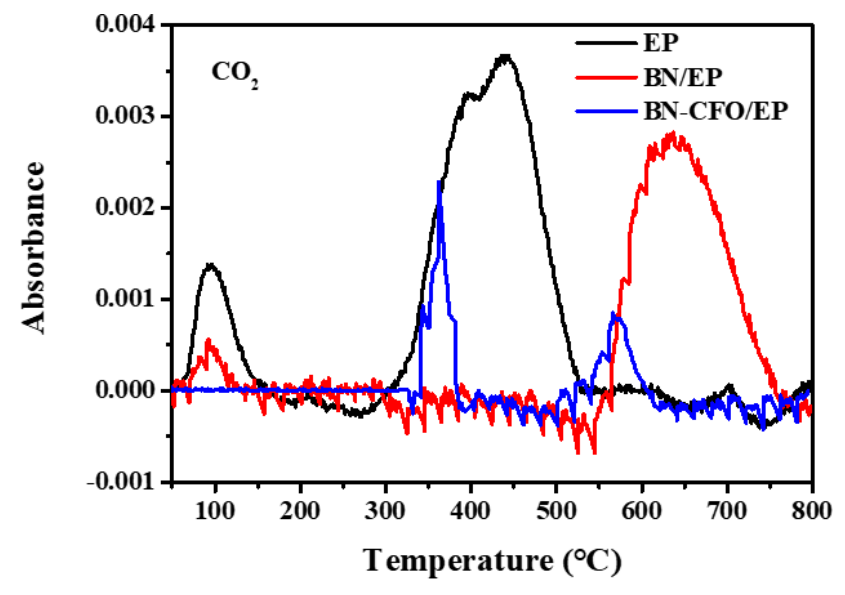

(b)

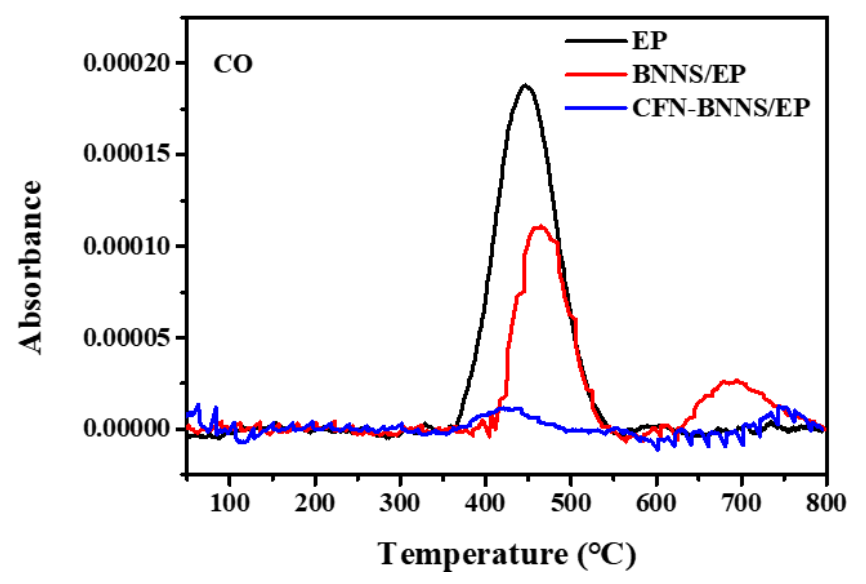

(d)

Fig. 13. Absorbance of pyrolysis products for $\mathrm{EP}$ and its nanocomposites versus time: (a) aromatic compounds, (b) $\mathrm{CO}_{2}$, (c) hydrocarbons, and (d) CO.

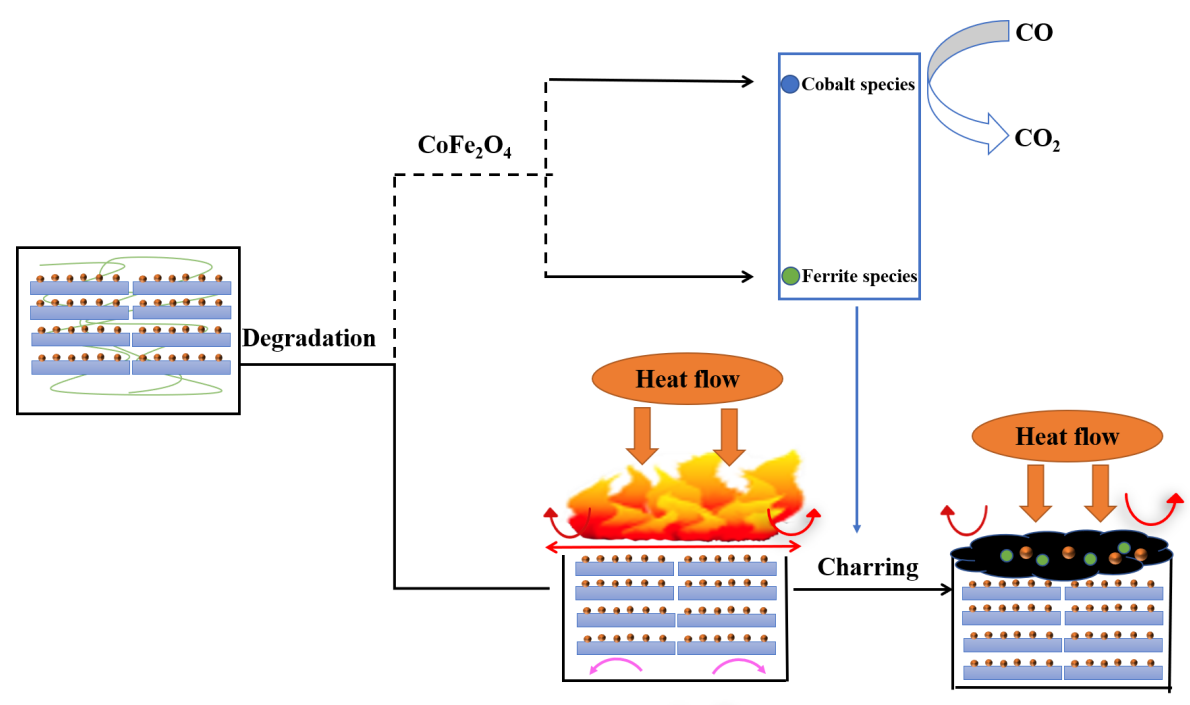

CFN-BNNSS Degradation products

Flammable gases

Fig. 14. Schematic illustration of flame retardation mechanism of CFN-BNNS. 


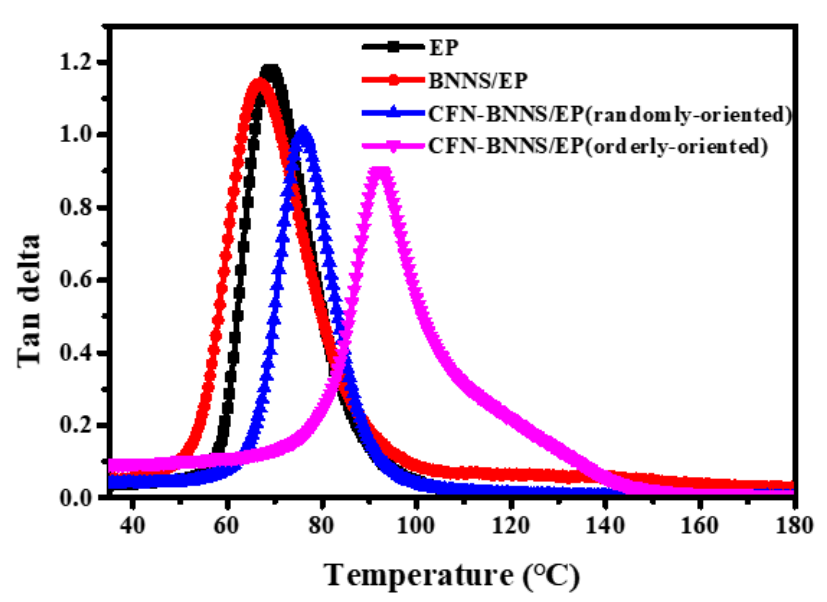

(a)

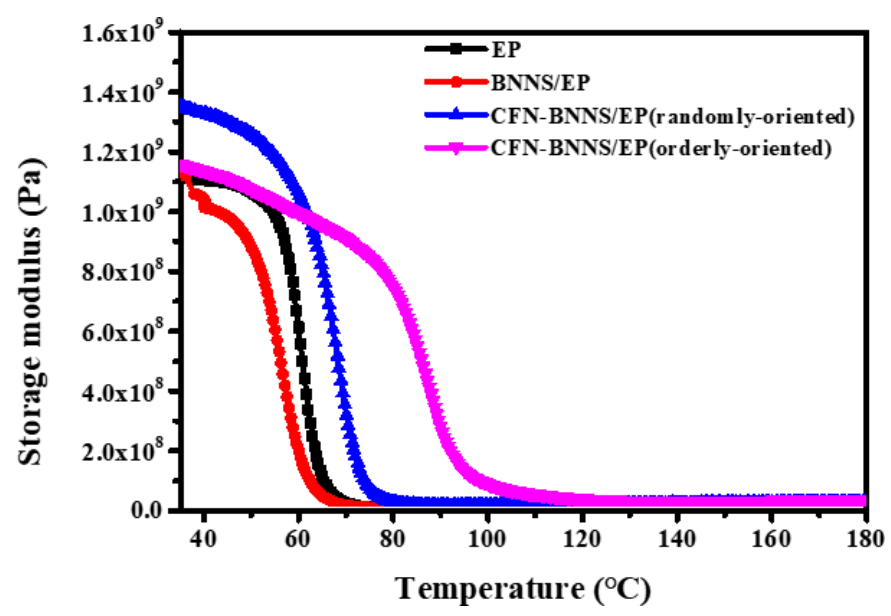

(b)

Fig. 15. Variations in tan delta (a) and storage modulus (b) of EP and its nanocomposites with temperature.

protective char layer and migrate onto the surface of char layer as well, thereby enhancing the thermal stability of the chars. ${ }^{38}$ The cobalt species can enhance the oxidation of $\mathrm{CO}$ to afford $\mathrm{CO}_{2}$, thereby reducing the toxic hazards. ${ }^{39}$ In summary, orderly aligned BNNS as a physical barrier can well prevent the transfer and diffusion of oxygen and heat. In the meantime, CFN can catalyze the degradation of EP to afford excessive chars on polymer surface; and during combustion it can also generate ferrite species to promote the polymer degradation and afford additional protective char layer as well as cobalt species to enhance the oxidation of $\mathrm{CO}$ and reduce the toxic hazards. Such combinative effects between BNNS and CFN account for the great improvement in the flame-retardant ability of EP upon incorporation of the orderly aligned CFN-BNNS nanofiller.

\subsection{Dynamic mechanical analysis}

Dynamic mechanical analysis can be used to test the physical and chemical changes of epoxy resins and their nanocomposites. ${ }^{40,41}$ The tan delta and storage moduli of EP and EP-matrix nanocomposites are presented in Fig. 15. The introduction of $3 \mathrm{wt} . \%$ BNNS leads to a little decrease in the glass transition temperature $(T \mathrm{~g})$ of EP, likely because of the re-stacking of BNNS in EP matrix [Fig. 15(a)]. The CFN-BNNS/EP composites, whether introduction of disordered CFN-BNNS or ordered CFN-BNNS, have a higher $T \mathrm{~g}$ than pristine EP and BNNS/EP. Particularly, EP filled with the orderly oriented CFN-BNNS nanofiller has the highest $T \mathrm{~g}$ value, which well corresponds to the abovementioned CCT data. Moreover, there is no difference between disordered CFN-BNNS and orderly-oriented CFN-BNNS in terms of their ability to enhance the storage modulus of EP, but the latter is advantageous in maintaining the thermal mechanical properties of EP [Fig. 15(b)]. This indicates that the CFN-BNNS nanofiller orderly aligned under magnetic field can well reduce the fire risk and toxic hazards of EP matrix without damage to the thermal mechanical properties.

\section{Conclusions}

CFN-BNNS nanohybrid is prepared as a flameretardant nanoadditive of EP via a simple hydrothermal process. The as-obtained CFN-BNNS nanofiller is induced to achieve orderly alignment in EP matrix under magnetic field in order to reduce the fire risk and toxic hazrads of EP upon combustion. Characterizations by XRD, Raman spectrometry, TEM, and SEM demonstrate that the CFNBNNS nanohybrid is composed of CFN nanoparticle uniformly dispersed on BNNS surface. The CFNBNNS nanofiller among EP results in improving the char residues and mechanical properties of EP and reducing its fire risk as well as toxic hazards, and the ordered one is advantageous over the disordered one in reducing the fire risk and toxic hazard. This is attributed to the combinatory effect between the BNNS and CFN components of the orderly aligned CFN-BNNS nanofiller. Namely the orderly aligned BNNS as a nanobarrier can better prevent the heat 
and oxygen into EP matrix as compared with the disordered one. CFN can catalyze the degradation of EP to afford excessive chars on polymer surface, and it is also liable to decompose during combustion thereby affording ferrite species to facilitate EP degradation as well as cobalt species to enhance $\mathrm{CO}$ oxidation.

\section{Acknowledgments}

This paper was supported by the National Natural Science Foundation of China (Grant No. 21371050) and the Program for Innovative Research Team from the University of Henan Province (Grant No. 17IRTSTHN004).

\section{References}

1. Y. Zhan, J. Zhang, X. Wan, Z. Long, S. He and Y. He, Appl. Surf. Sci. 436, 756 (2018).

2. Y. W. Huang, S. Q. Song, Y. Yang, K. Cao, J. X. Yang and G. J. Chang, J. Mater. Chem. A. 3, 15935 (2015).

3. D. Wang, Q. Zhang, K. Zhou, W. Yang, Y. Hu and X. Gong, J. Hazard. Mater. 278, 391 (2014).

4. C. Gérard, G. Fontaine, S. Bellayer and S. Bourbigot, Polym. Degrad. Stab. 97, 1366 (2012).

5. S. D. Jiang, Z. M. Bai, T. G, S. L, A. A. Stec, T. R. Hull, J. Zhan and Y. Hu, J. Mater. Chem. A. 2, 17341 (2014).

6. Y. Cao, G. Li and X. Li, Chem. Eng. J. 292, 207 (2016).

7. Q. Kong, T. Wu, H. Zhang, Y. Zhang, M. Zhang, T. Si, L. Yang and J. Zhang, Appl. Clay. Sci. 146, 230 (2017).

8. X. Feng, W. Xing, L. Song and Y. Hu, J. Mater. Chem. A. 2, 13299 (2014).

9. Y. Shi, B. Yu, K. Zhou, R. K. Yuen, Z. Gui, Y. Hu and S. Jiang, J. Hazard. Mater. 293, 87 (2015).

10. S. D. Jiang, Z. M. Bai, G. Tang, Y. Hu and L. Song, Ind. Eng. Chem. Res. 53, 6708 (2014).

11. W. Wang, H. Pan, Y. Shi, Y. Pan, W. Yang, K. M. Liew, L. Song and Y. Hu, Compos. Part A-Appl. S. 80, 259 (2016).

12. C. Liu, H. Yan, Z. Chen, L. Yuan and T. Liu, J. Mater. Chem. A. 3, 10559 (2015).

13. Q. R. Zhang, Z. W. Li, X. H. Li, L. G. Yu and Z. S. Wu, Mater. Res. Express. 5, 095019 (2018).

14. G. Li, H. Wang, Y. Gao, S. Liu, R. Tian and Q. Wang, Ceram. Int. 44, 7172 (2018).

15. X. Liu, D. M. Xu, Y. L. Wang, Y. Zhou and J. W. Hao, J. Therm. Anal. Calorim. 125, 245 (2016).

16. X. Chen, L. Liu, C. Jiao, Y. Qian and S. Li, High Perform. Polym. 27, 412 (2014).
17. C. Z. Yang, Z. W. Li, L. G. Yu, X. H. Li and Z. J. Zhang, Ind. Eng. Chem. Res. 56, 7720 (2017).

18. B. Yu, W. Y. Xing, W. W. Guo, S. L. Qiu, X. Wang, S. Lo and Y. Hu, J. Mater. Chem. A. 4, 7330 (2016).

19. W. Cai, X. Mu, Y. Pan, W. Guo, J. Wang, B. Yuan, X. Feng, Q. Tai and Y. Hu, Polym. Advan. Technol. 29, 2545 (2018).

20. W. Cai, W. Guo, Y. Pan, J. Wang, X. Mu, X. Feng, B. Yuan, B. Wang and Y. Hu, Compos. Part AAppl. S. 111, 94 (2018).

21. Z. Li, S. I. M. Lira, Lu. Zhang, D. F. Expósito, V. B. Heeralal and D. Y. Wang, Polym. Degrad. Stab. 157, 119 (2018).

22. K. Kim and J. Kim, Int. J. Therm. Sci. 100, 29 (2016).

23. K. Kim, H. Ju and J. Kim, Compos. Sci. Technol. 123, 99 (2016).

24. Q. R. Zhang, Z. W. Li, X. H. Li, L. G. Yu, Z. J. Zhang and Z. S. Wu, Chem. Eng. J. 356, 680 (2019).

25. M. Du, Y. Z. Wu and X. P. Hao, Cryst. Eng. Comm. 15, 1782 (2013).

26. L. Chen, D. Ding, C. Liu, H. Cai, Y. Qu, S. Yang, Y. Gao and T. Cai, Chem. Eng. J. 334, 273 (2018).

27. W. Cai, N. Hong, X. Feng, W. Zeng, Y. Shi, Y. Zhang, B. Wang and Y. Hu, Chem. Eng. J. 330, 309 (2017).

28. H. Jin, Y. Li, X. Li, Z. Shi, H. Xia, Z. Xu and G. Qiao, Mater. Lett. 175, 244 (2016).

29. K. V. Chandekar and K. M. Kant, Superlattice. Microst. 111, 610 (2017).

30. C. Zhang, Y. He, F. Li, H. Di, L. Zhang and Y. Zhan, J. Alloys. Compd. 685, 743 (2016).

31. C. Yuan, B. Duan, L. Li, B. Xie, M. Huang and X. Luo, ACS Appl. Mater. Interfaces. 7, 13000 (2015).

32. H. Chen, Y. Li, S. Wang, Y. Li and Y. Zhou, J. Membrane. Sci. 546, 22 (2018).

33. J. Wang, B. Yuan, W. Cai, S. Qiu, Q. Tai, H. Yang and Y. Hu, Mater. Chem. Phys. 214, 209 (2018).

34. H. Qu, C. Liu, W. Wu, L. Chen and J. Xu, J. Therm. Anal. Calorim. 115, 1081 (2013).

35. S. G. Wang, R. Gao and K. Q. Zhou, J. Colloid. Interf. Sci. 536, 127 (2019).

36. D. S. Muratov, D. V. Kuznetsov, I. A. Il'inykh, I. N. Burmistrov and I. N. Mazov, Compos. Sci. Technol. 111, 40 (2015).

37. D. Wang, Y. C. Kan, X. J. Yu, J. J. Liu, L. Song and Y. Hu, J. Hazard. Mater. 320, 504 (2016).

38. X. Chen, M. Li, J. Zhuo, C. Ma and C. Jiao, J. Therm. Anal. Calorim. 123, 439 (2015).

39. X. Xie, Y. Li, Z. Q. Liu, M. Haruta and W. Shen, Nature. 458, 746 (2009).

40. C. Ma, S. Qiu, B. Yu, J. Wang, C. Wang, W. Zeng and Y. Hu, Chem. Eng. J. 322, 618 (2017).

41. X. Zhou, L. S. Qiu, W. Y. Xing, C. Gangireddy, G. Zhou and Y. Hu, ACS Appl. Mater. Interfaces. 9, 29147 (2017). 